\title{
An Investigation of the Accuracy of a New Technique for Surgical Repositioning a Maxilla
}

\author{
Chad L. Westfall \\ West Virginia University
}

Follow this and additional works at: https://researchrepository.wvu.edu/etd

\section{Recommended Citation}

Westfall, Chad L., "An Investigation of the Accuracy of a New Technique for Surgical Repositioning a Maxilla" (2013). Graduate Theses, Dissertations, and Problem Reports. 180.

https://researchrepository.wvu.edu/etd/180

This Thesis is protected by copyright and/or related rights. It has been brought to you by the The Research Repository @ WVU with permission from the rights-holder(s). You are free to use this Thesis in any way that is permitted by the copyright and related rights legislation that applies to your use. For other uses you must obtain permission from the rights-holder(s) directly, unless additional rights are indicated by a Creative Commons license in the record and/ or on the work itself. This Thesis has been accepted for inclusion in WVU Graduate Theses, Dissertations, and Problem Reports collection by an authorized administrator of The Research Repository @ WVU. For more information, please contact researchrepository@mail.wvu.edu. 


\title{
An Investigation of the Accuracy of a New Technique for Surgical
} Repositioning a Maxilla

\author{
Chad L. Westfall D.D.S \\ A THESIS \\ Submitted to: \\ The School of Dentistry \\ at West Virginia University \\ in partial fulfillment of the requirements \\ for the degree of \\ Master of Science \\ In \\ Orthodontics \\ Peter Ngan, D.M.D., Chair \\ Timothy Tremont, D.D.S., M.S. \\ Bryan Weaver, D.D.S., M.D. \\ West Virginia University \\ Department of Orthodontics \\ Morgantown, West Virginia 2013
}




\title{
ABSTRACT
}

\section{An Investigation of the Accuracy of a New Technique for Surgical Repositioning a Maxilla}

\author{
Chad L. Westfall, D.D.S., Peter Ngan, D.M.D, Tim Tremont D.M.D., M.S., Bryan \\ Weaver, D.D.S., M.D.
}

Objectives: The purpose of this study was to test the method of the Four Faces of Orthognathic Surgery $\AA^{\circledR}$ in regards to surgical accuracy and the ability to transfer this method to an academic setting. Methods: An experimental group consisted of 15 patients from a university setting and 17 patients from a private practice setting. Lateral cephalograms were taken immediately prior to the orthognathic procedure and post-operatively within six weeks. Pre-surgical, post-surgical cephalograms, and the hand generated surgical predictions were collected from the sample. The differences of planned and actual changes to incision were then analyzed to determine whether or not a statistical significance existed with respect to the following variables: surgical team, surgical complexity, and direction of maxillary movement. Results: The private practice sample evaluated in this study shows that $100 \%$ of the patients were treated to within $1 \mathrm{~mm}$ of prediction. The university team sample had a greater variation in surgical accuracy than the private practice team with $87 \%$ of the patients treated within $2 \mathrm{~mm}$ of prediction and $53 \%$ treated within $1 \mathrm{~mm}$ of prediction. However, this variation is not statistically significant. When surgical complexity and the primary direction of maxillary movement were compared, no significant differences were found. Conclusions: The Four Faces of Orthognathic Surgery ${ }^{\circledR}$ is a significantly accurate method of surgically repositioning the maxilla to a planned treatment goal and is a very transferable method to assure accurate repositioning of a maxilla in an academic setting. 


\section{DEDICATION}

To my amazing wife, Caitlin. You are my partner-in-crime, best friend, and biggest supporter. I greatly appreciate your sacrifices over these three years. Thanks for always being there.

To my parents, John and Pat, for always believing in me and my potential. Thank you for instilling in me the work ethic and discipline necessary to pursue my dreams and to succeed in life.

To my in-laws, Butch and Janet, thanks for all the encouragement, support, and great home cooked meals.

To GOD, who has blessed, and continues to bless me with more than I could ask for or deserve. 


\section{ACKNOWLEDGEMENTS}

Dr. Peter Ngan - Thank you so much for giving me a chance. Your help and guidance throughout the last three years are very much appreciated.

Dr. Bryan Weaver - Thank you being a good friend and for serving on my research committee.

Dr. Tim Tremont - Thank you for the use of your records in my research project and being a wonderful clinical instructor.

Dr. Erdogan Gunel - Thank you for your timely calculations of my statistics. Your work is greatly appreciated.

Drs. Jarrett, Hazey, Tremont, McFarland, Dempsey, Kirsch, Gilmore, Sebbahi,Foley, Boyles, Martin - Thank you for your continued dedication to our program. I have learned so much from each of you and appreciate the time you sacrifice to make our program so great.

Carrie, Karen, Leona, Hillary, Marsha - Thanks to each of you for putting up with me and making the last three years of clinic so wonderful. I really enjoyed our time together. You are all much appreciated.

Alice and Doyoung - Good luck to both of you in whatever life brings you. I know you will both do great.

Deepa, Nicole, Lance, Nick, Travis, and Jen, as well as former residents Rob and Ronnie - Thank you so much for your friendship and all the good times we shared together. You all have made our time here in West Virginia such a wonderful experience. I wish you all the best. 


\section{Table of Contents}

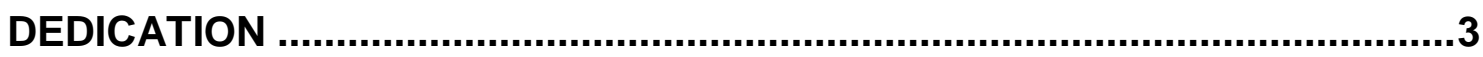

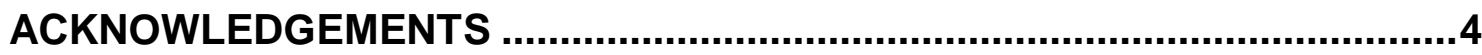

LIST OF TABLES

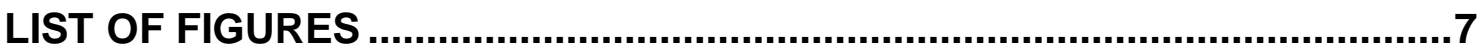

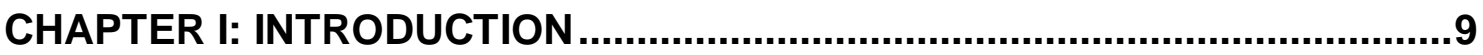

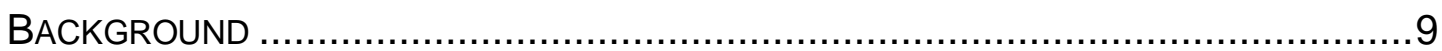

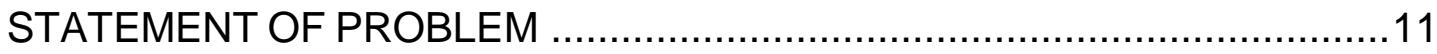

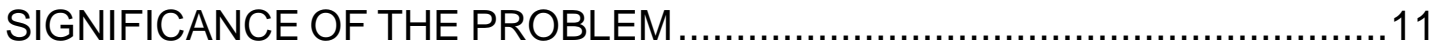

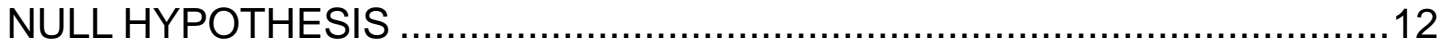

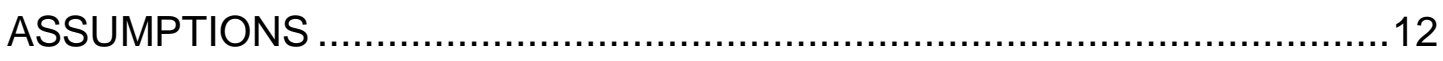

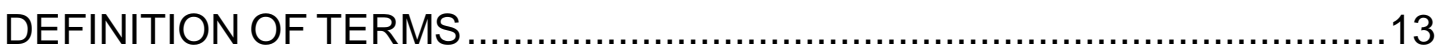

CHAPTER II: REVIEW OF LITERATURE.................................................17

ETIOLOGY OF MALOCCLUSIONS AND THE NEED FOR ORTHODONTIC THERAPY.........17

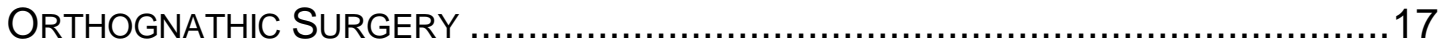

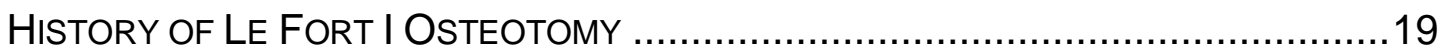

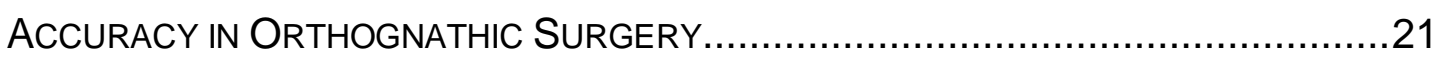

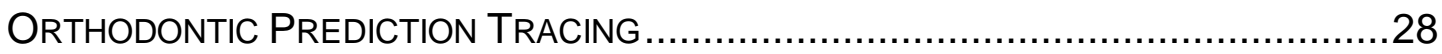

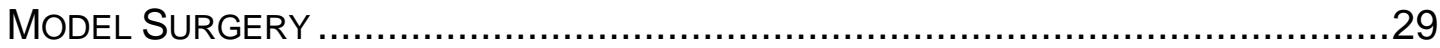

FOUR FACES OF ORTHOGNATHIC SURGERY@ AND THE TRIDIMENSIONAL

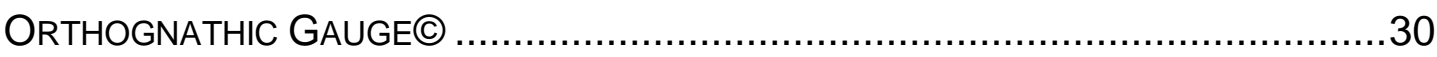

CHAPTER III: MATERIALS AND METHODS .............................................33

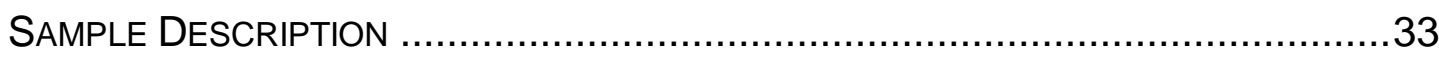

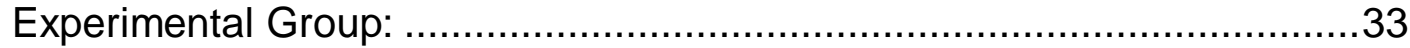

TREATMENT PROTOCOL ...................................ERROR! BOOKMARK NOT DEFINED.

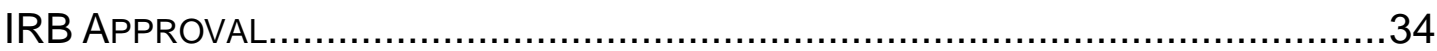

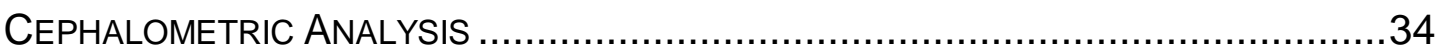

ESTABLISHING THE TRANSVERSE FACIAL PLANE .ERROR! BOOKMARK NOT DEFINED. METHODS TO MEASURE RESULTS ......................ERROR! BOOKMARK NOT DEFINED.

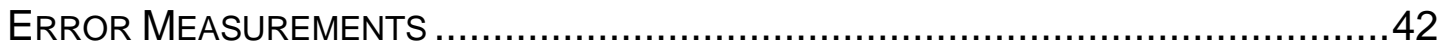

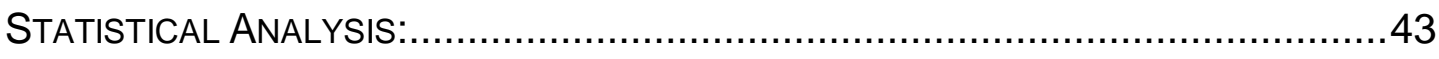

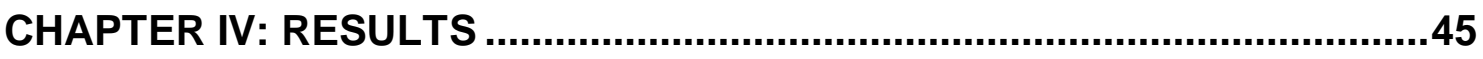

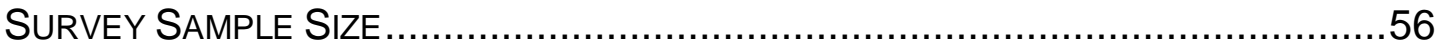

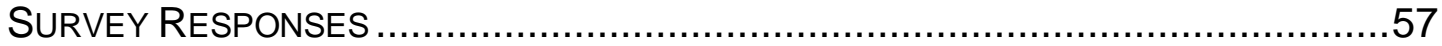

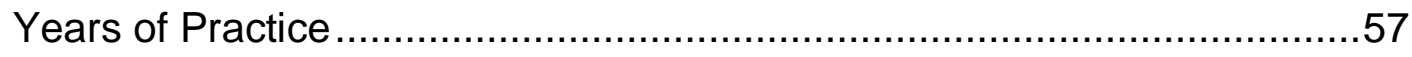

Prevalence of Orthognathic Surgery ..................................................58 


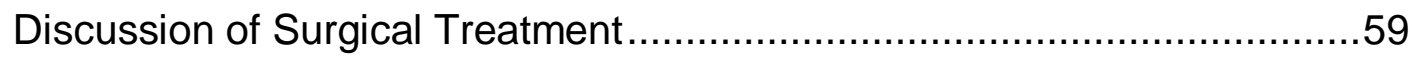

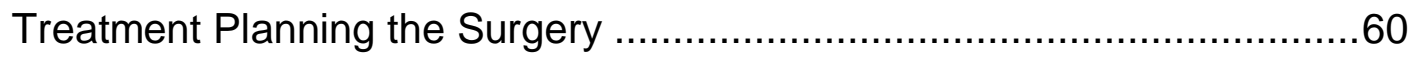

Private Practice or University Setting Oral Surgeons ...............................61

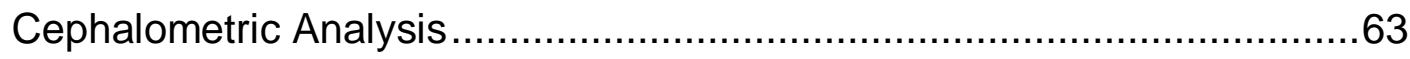

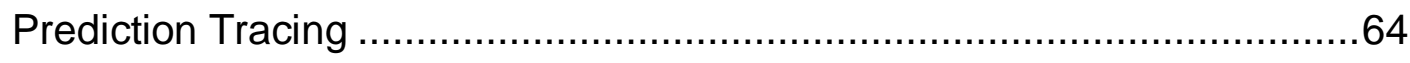

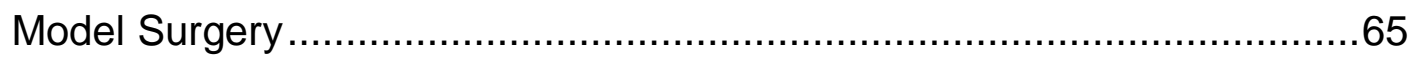

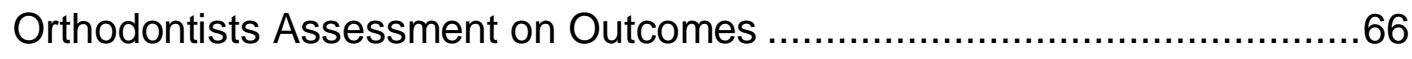

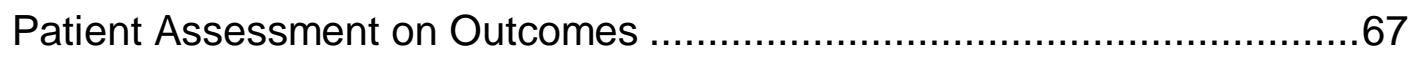

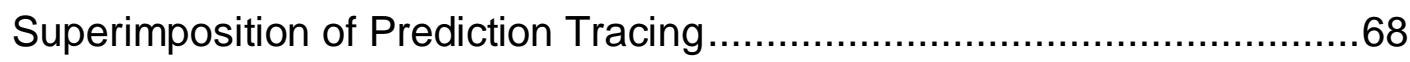

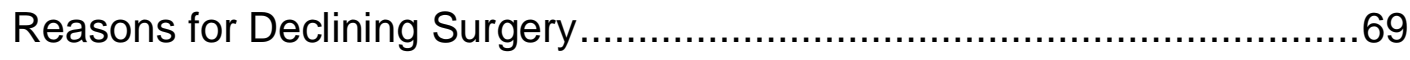

Overall average discrepancy between predicted and actual results ...........45

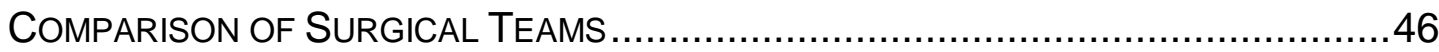

EFFECT OF SURGICAL COMPLEXITY.......................................................

EFFECT OF DIRECTION OF PRIMARY MAXILLARY MOVEMENT ............................50

RELIABILITY OF VARIABLE MEASUREMENTS...............................................

CHAPTER V: DISCUSSION...................ERROR! BOOKMARK NOT DEFINED. CHAPTER VI: SUMMARY AND CONCLUSIONS ...ERROR! BOOKMARK NOT DEFINED.

CONCLUSIONS .............................................ERROR! BOOKMARK NOT DEFINED.

CHAPTER VII: RECOMMENDATIONS FOR FUTURE RESEARCH.....ERROR! BOOKMARK NOT DEFINED.

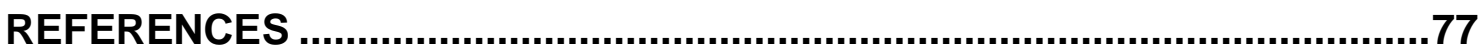




\section{List of Tables}

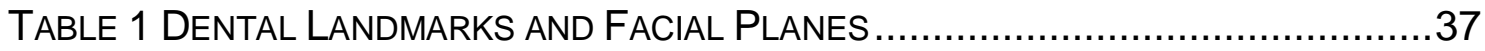

TABLE 2 SKELETAL LANDMARKS FOR SUPERIMPOSITION ....................................38

TABLE 3 DISCREPANCY BETWEEN PREDICTED AND ACTUAL RESULTS ....................45

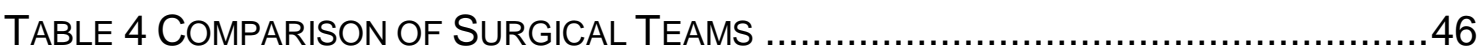

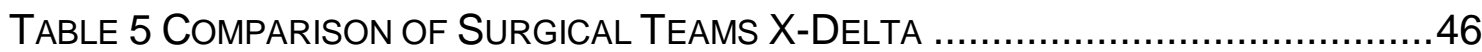

TABLE 6 COMPARISON OF SURGICAL TEAMS Y-DELTA ......................................47

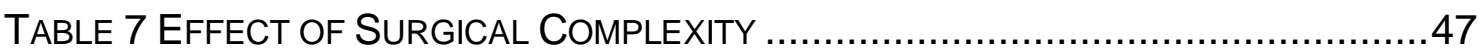

TABLE 8 EFFECT OF SURGICAL COMPLEXITY X-DELTA …...............................48

TABLE 9 EFFECT OF SURGICAL COMPLEXITY Y-DELTA …................................48

TABLE 10 EFFECT OF DIRECTION OF PRIMARY MAXILLARY MOVEMENT .....................50

TABLE 11 EFFECT OF DIRECTION OF PRIMARY MAXILLARY MOVEMENT X-DELTA .........50

TABLE 12 EFFECT OF DIRECTION OF PRIMARY MAXILLARY MOVEMENT Y-DELTA ........51

\section{List of Figures}

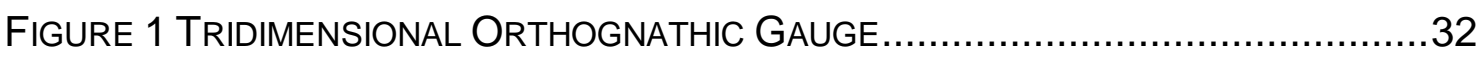

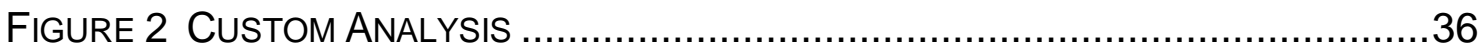

FIGURE 3 PREDICTION TRACING SUPERIMPOSED ON PRE-SURGICAL CEPHALOGRAM ..39

FIGURE 4 PREDICTION TRACING ON POST-SURGICAL CEPHALOGRAM......................40

FIGURE 5 MEASUREMENT OF TOOTH MOVEMENT ............................................. 44

FIGURE 6 DISTRIBUTION OF PRACTICING ORTHODONTICS ................................57

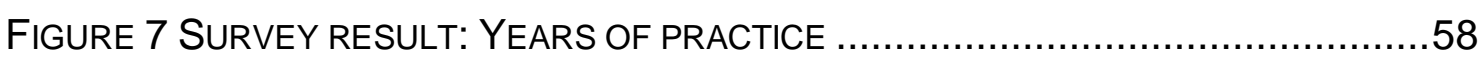

FIGURE 8: SURVEY RESULT: PATIENTS THAT WOULD REQUIRE SURGERY FOR OPTIMAL DENTOFACIAL OUTCOME .59 


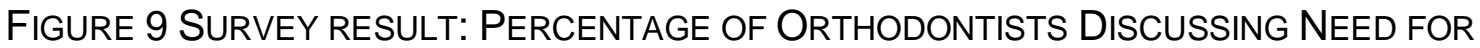

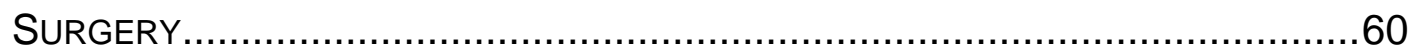

FIGURE 10 SURVEY RESULT: WHO TREATMENT PLANS THE SURGERY....................61

FIGURE 11 SURVEY RESULTS: SETTING IN WHICH ORAL SURGEON PRACTICES...........62

FIGURE 12 SURVEY RESULTS: PERCENTAGE THAT USE CEPHALOMETRIC ANALYSIS TO

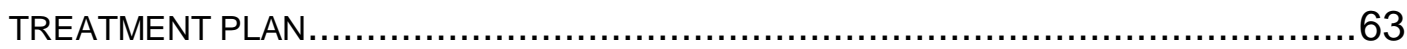

FiguRE 13 SURVEY RESULT: PERCENTAGE OF ORTHOdONTISTS THAT USE A

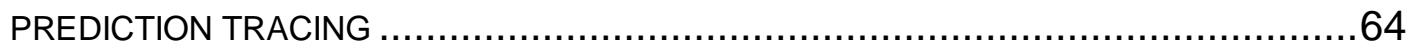

FIGURE 14 SURVEY RESULTS: WHO DOES THE MODEL SURGERY .........................65

FIGURE 15 SURVEY RESULTS: ORTHODONTISTS ASSESSMENT ON SURGICAL

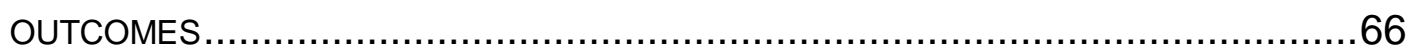

FIGURE 16 SURVEY RESULTS: PATIENTS ASSESSMENT ON SURGICAL OUTCOMES .....67

FIGURE 17 SURVEY RESULTS: PERCENTAGE SUPERIMPOSITION OF PREDICTION

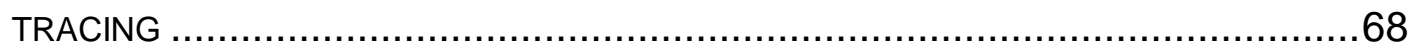

FIGURE 18 SURVEY RESULTS: REASONS FOR DECLINING SURGERY......................69 


\section{CHAPTER I: INTRODUCTION}

\section{Background}

Orthodontists are routinely involved in the treatment of severe malocclusions. When treating severe dentofacial deformities a combination of orthodontics and orthognathic surgery treatment is often the most appropriate treatment option. While few patients and clinicians question the functional benefits of orthognathic surgery, the esthetic results that accompany surgery of the bony foundation of the face are equally powerful, if not more so. ${ }^{1}$ An orthodontist's ability to predict the outcome of any orthognathic procedure relies on a surgeon's ability to accurately reproduce the desired skeletal movements and on the understanding of the soft tissue changes associated with those

movements. ${ }^{2}$ The surgical prediction tracing is a meaningful tool that facilitates the communication between the orthodontist, oral surgeon, and patient. ${ }^{3}$

A Le Fort I maxillary osteotomy is a relatively accurate procedure but there is a wide range of discrepancy. ${ }^{4}$ The stability and predictability of orthognathic surgical procedures is reported to vary by the direction of the surgical movement, the type of fixation, and the surgical technique employed, largely in that order of importatnce. ${ }^{5}$ The placement of the maxilla in 3 planes of space will greatly affect the amount of mandibular autorotation, and therefore the extent to which a mandibular osteotomy and possible genioplasty are 
required. $^{2}$ Therefore, accurate placement of the maxilla in surgery is essential for predictable esthetic and functional outcomes. The ideal placement of the maxilla can be a subject of debate and often a matter of opinion, and is outside the objectives of this study.

A private practice study conducted at the University of Alabama by Jacobson and Sarver ${ }^{2}$ found that in $43 \%$ of the subjects, the overall surgical outcomes were within $1 \mathrm{~mm}$ of the prediction and in $80 \%$ of the subjects the actual results were within two $\mathrm{mm}$ of the prediction. ${ }^{2}$ Semaan and Goonewardene ${ }^{4}$ at the University of Western Australia found that $66 \%$ of the subjects were within $2 \mathrm{~mm}$ of prediction and $26 \%$ of the results were within $1 \mathrm{~mm}$ of the prediction. ${ }^{4}$

Techniques such as free hand repositioning and internal reference points (IRP) are approaches used by several surgeons, but external reference points (ERP) are currently the most precise method to use during Le Fort I osteotomy. ${ }^{7}$

Dr. Timothy Tremont has developed a comprehensive method for orthognathic surgery known as The Four Faces of Orthognathic Surgery ${ }^{\circledR}$. This approach involves both pre-surgical planning and surgical verification of the planned treatment goals. He proposes this method enables an oral/maxillofacial surgeon to precisely achieve the desired changes that were planned by the orthodontist and surgeon prior to surgery. The Tri-dimensional Orthognathic Gauge (TOG) ${ }^{\mathrm{TM}}$ was designed to verify the planned position of the maxilla in 
three planes of space. ${ }^{6}$ Tremont has stated that use of the method and device result in accuracy of surgical outcomes within $1 \mathrm{~mm} .{ }^{6}$ This instrument verifies in the operating room the planned changes to incision in both the antero-posterior direction and vertical directions. It also confirms the dental midline matches with the facial midline.

The objective of this study was to investigate the accuracy of surgeons utilizing the Four Faces of Orthognathic Surgery ${ }^{\circledR}$ and the $\mathrm{TOG}^{\mathrm{TM}}$ relative to the planned vertical and horizontal changes to the maxilla.

\section{STATEMENT OF PROBLEM}

There is no consensus on a method to assure surgical accuracy for a Le Fort I osteotomy. The accuracy of a Le Fort I osteotomy using the Four Faces of Orthognathic Surgery ${ }^{\circledR}$ and the Tridimensional Orthognathic Gauge (TOG ${ }^{\mathrm{TM}}$ ) needs to be verified in a private practice and academic setting.

\section{SIGNIFICANCE OF THE PROBLEM}

Several articles in current orthodontic literature discuss the accuracy in predicting surgical outcomes regarding hard and soft tissue. The accuracy of soft tissue prediction has been and continues to be an area of strong interest in 
both the orthodontic and surgical literature. ${ }^{2}$ These predictions of soft tissue changes are based on algorithms of pre-determined surgical movements of hard tissues. ${ }^{8}$ Therefore, is it adequate to predict soft tissue change if the surgeon cannot accurately place the hard tissue in the planned position $?^{6}$ The result of this study will provide information on the accuracy of planned surgical hard tissue movements using the method of the Four Faces of Orthognathic Surgery ${ }^{\circledR}$ and the Tridimensional Orthognathic Gauge (TOG ${ }^{\mathrm{TM}}$ )

\section{NULL HYPOTHESIS}

1. The Four Faces of Orthognathic Surgery ${ }^{\circledR}$ is not a significantly more accurate method of surgically repositioning the maxilla to a planned treatment goal.

2. The accuracy of this method cannot be transferred to another surgical team in an academic setting.

\section{ASSUMPTIONS}

1. Case selection was made on the basis of the following criteria: 
- Patients received a LeFort I maxillary osteotomy alone or combined with a mandibular osteotomy or genioplasty

- Preoperative and immediately postoperative lateral cephalometric radiographs were of good quality, and the selected referents and landmarks were not obscured

- The surgical team attempted to follow the presurgical prescription

- The radiographs showed no apparent misalignment of the subject's head in the cephalogram, and the same machine and technique used for each patient to minimize magnification error

\section{DEFINITION OF TERMS}

- Accuracy

- The presurgical prediction tracing of the maxillary incisor superimposes precisely on the post-surgical cephalometric radiograph $^{6}$

- Cephalogram:

- A cephalometric radiograph.

- Cephalometric Radiograph: 
- A lateral head film made with the patient in a fixed reproducible position with precise relationships between x-ray source, subject, and film. The generally accepted distances between $\mathrm{x}$-ray source and the center of the subject are 5 feet or $150 \mathrm{~cm}$. The distance between the subject and film is usually $15 \mathrm{~cm}$, but may be standardized at a different value or varied with patient size and recorded for each exposure.

- Cephalometrics:

- The scientific measurement of the bones and teeth of the cranium by utilizing a fixed, reproducible position for the exposure of a lateral head film.

- Cephalometric Analysis:

- A description of positions and relationships of various skeletal, dental and soft tissue components based on a number of landmarks.

- Cephalometric Landmark:

- A point located on a cephalometric radiograph from which lines, planes, and angles may be constructed to analyze the configuration and relationship of elements of the craniofacial skeleton. 
- Cephalometric tracing:

- A tracing of structures from a cephalometric radiograph, made on translucent drafting paper or digitized on computer software for purposes of measurement and evaluation.

- Incision Superious

- The incisal point of the most prominent maxillary central incisor. This point is measured in the vertical and antero-posterior dimensions

- Landmark

- A fixed, reproducible (anatomical) point of reference on a radiograph.

- Orthognathic Surgery

- To surgically reposition the maxilla, mandible, and/ or chin for patients too old for growth modification and for conditions too severe for orthodontic camoflauge

- Referent

- A variable, reproducible (anatomical) point related to a landmark on a radiograph.

- Transverse plane 
- Is an imaginary plane that divides the body into superior and inferior parts. It is perpendicular to the coronal and sagittal planes. This was established using a lase

- Vertical Reference Line

- A line drawn perpendicular to the transverse plane

- Tridimensional Orthognathic Gauge

- The TOG is a measuring device that can target and verify the desired position of the maxillary teeth (jaw) precisely in all three dimensions during orthognathic surgery. ${ }^{6}$ It is an integral part of the Four Faces of Orthognathic Surgery. The Four Faces consists of three preoperative planning stages: clinical evaluation (Clinical Face), cephalometric prediction tracing (Cephalometric Face), model surgery (Articulator Face) and the final intraoperative stage (Surgical Face). ${ }^{6}$ The goal is to have the presurgical prediction accurately superimpose on the post-surgical cephalograph.

- VTO - Visual Treatment Objective

- An estimation of the result of treatment used to assess how tooth and bone movement to correct the bite will impact the face 


\section{CHAPTER II: REVIEW OF LITERATURE}

\section{Etiology of malocclusions and the need for orthodontic therapy}

A malocclusion is not a disease. A malocclusion is a symptom of disturbances in one or more of the components that influence the occlusion ${ }^{5}$. A dentofacial deformity is the result of distortions in the normal skeletal growth. The primary etiologic factors associated with orthodontic problems have been cited as hereditary influences, environmental influences, and muscle dysfunction. ${ }^{3}$ The underlying abnormality may be present at birth or may become evident as the patient grows and develops or may be the result of traumatic injuries. ${ }^{3}$ Physical appearance is critically important in our society.

\section{Orthognathic Surgery}

Orthognathic surgery has created new and exciting opportunities in the treatment of patients with dentofacial deformities and provides the orthodontist with options other than compromised treatment for patients with skeletal disharmony ${ }^{9}$. The word orthognathic comes from the Greek word "orqos" meaning to straighten and "gnaqos" meaning jaw. Orthognathic surgery can involve surgical correction of abnormalities of the mandible, maxilla, or both. The overall goal of treatment is to improve function through correction of the underlying skeletal deformity. ${ }^{9}$ Traditional treatment planning in orthognathic 
surgery was based primarily on a system of clinical observation and a static set of records (models, radiographs) with the major emphasis of treatment planning directed to satisfy lateral cephalometric goals ${ }^{1}$. The most significant shortcoming of the dependence on the lateral cephalogram as the primary determinant of treatment goal setting is it did not take into account the resting and dynamic hard-soft tissue relationships ${ }^{1}$. However, a greater concern for esthetic aspects of surgery developed, such that facial soft tissue prediction became an integral part of preoperative planning and postoperative outcome assessment ${ }^{8}$. For patients whose orthodontic problems are so severe that neither growth modification nor camouflage offers a solution, surgical realignment of the jaw or repositioning of dentoalveolar segments is the only possible treatment ${ }^{5}$. However, a major factor in the patient's determination of the success of a procedure is the perceived esthetic outcome ${ }^{10}$. Nevertheless, restoring the orthognathic form of the face ultimately depends upon achieving the ideal facial esthetics of the individual patient, not simply restoring the average normative values of a population ${ }^{11}$.

Therefore, establishing and communicating realistic expectations and goals of the surgical procedure are vital so that the patient has a reasonable idea of the possible outcome. Communication between the orthodontist and the surgeon is also paramount, as the goals of the surgeon and the orthodontist may differ which can significantly affect the treatment plan ${ }^{12}$. 


\section{History of Le Fort I Osteotomy}

Maxillary deformities may manifest in any of the three planes of space: sagittal, axial, and coronal. Patients displaying abnormal facial anatomy often exhibit elements of maxillary and mandibular deformities. Orthognathic surgery of the maxilla was first described in 1859 by von Langenbeck for the removal of nasopharyngeal polyps. ${ }^{13}$ The first American report of a maxillary osteotomy was by Cheever in 1867 for the treatment of complete nasal obstruction secondary to recurrent epistaxis for which a right hemimaxillary down-fracture was used ${ }^{14}$.Over the next 70 years numerous authors described osteotomy techniques that mobilized the entire maxilla for the treatment of pathologic processes.

In 1901 Le Fort published his classic description of the natural planes of maxillary fracture ${ }^{15}$. Most of these techniques simply mobilized the maxilla to one degree or another, and then placed orthopedic forces on it to achieve the desired repositioning —a sort of unintentional distraction osteogenesis. These methods were associated with high levels of relapse. In 1921, a German surgeon, Herman Wassmund, reported his initial attempt to correct dentofacial deformity by maxillary osteotomy. Wassmund did not mobilize the maxilla after the osteotomy, but rather employed orthopedic traction during the postsurgical period to position the maxilla. In 1965 Obwegeser suggested complete 
mobilization of the maxilla so that repositioning could be accomplished without tension.

In the 1960s, American surgeons began to adopt intraoral surgical techniques for Le Fort I procedures. Before 1965 dentofacial deformity was treated by mandibular surgery alone, even though the skeletal problem presented by the patient may have been partly or entirely in the maxilla. The final result often was not satisfactory. Surgeons began to work more closely with orthodontists to diagnose and treat problems in patients with severe dentofacial deformity. Initially, surgical corrections of problems in both the maxilla and mandible were performed as separate or staged procedures because of the complexity of presurgical planning, the technical difficulty of the procedures, and the time required to complete each procedure ${ }^{16}$.

In the mid-1970s Bell and associates' research on the biologic basis of the hemodynamics and vascular supply of the maxilla during and after maxillary downfracture surgery of the Le Fort I maxillary osteotomy developed into the refined science and art that it is currently ${ }^{9}$. A Le Fort I osteotomy and surgery in the ramous of the mandible were now able to be done in combination, performed under the same anesthetic ${ }^{16-22}$. Numerous techniques for Le Fort I maxillary osteotomy have been described and reflect a strong tendency toward operator preference ${ }^{23}$. This indicates the need for very careful planning before 
surgery; and the proper sequencing of two-jaw procedures in the operative room is paramount.

\section{Accuracy in Orthognathic Surgery}

Since orthognathic surgery is elective, it is imperative that the surgeon strives to provide the patient with the most accurate surgical repositioning possible. ${ }^{24}$ Esthetic demands determine successful parameters, and a few millimeters of inaccuracy of the upper incisor position can affect patient's satisfaction. ${ }^{10}$ Approaches such as free hand repositioning ${ }^{25}$ and internal reference marks ${ }^{26}$ (IRP) are used by several surgeons, but external reference points (ERP) are currently the most precise method to use during Le Fort I osteotomy. ${ }^{24,27}$ Even though ERP with intermediate splints has been shown to be more precise than IRP, it is still difficult to achieve accuracy in the three planes of space, especially during multidirectional moves ${ }^{7,24,27}$.

Several articles in the literature have looked at this topic and are divided into two different categories: studies which looked at the accuracy of the surgical prediction software, and those that compared the predicted surgical

movements against the observed surgical movements. Six studies ${ }^{28-33}$ were found that assessed mostly the algorithms used to predict soft and hard tissue profiles produced by different software programs. However, these studies assume that the surgeon always placed the jaws in the planned position, and then assessed whether the software accurately predicted the soft tissue profile. 
The question still arises of whether or not the surgeon accurately achieved the goals set by the prediction tracing.

Procedures involving the maxilla alone or in combination with a mandibular procedure are much more complex and variable. ${ }^{35}$ The placement of the maxilla in three planes will greatly affect the amount of mandibular autorotation, and therefore the extent to which a mandibular osteotomy and possible genioplasty are required. ${ }^{9}$ Therefore, the accurate placement of the maxilla in surgery is essential for predictable esthetic and functional outcomes. Four recent studies ${ }^{2,4,35,36}$ were found which directly compared pre-surgical prediction tracings to immediate post-surgical radiographs to determine how accurately the maxilla or the maxilla and mandible were positioned.

The Jacobson and Sarver study ${ }^{2}$ evaluated 46 patients selected by one orthodontist and eight oral surgeons. This study did not mention how the maxilla was positioned or monitored during the surgery. Pre-surgical prediction tracings and immediate post-surgical tracings were superimposed on SellaNasion. A $2 \mathrm{~mm}$ or greater discrepancy was noted for 20 to $30 \%$ of the patients. The authors conclude that Le Fort I surgery can be very accurate, but can have a wide range of discrepancy. ${ }^{2}$

This study also assessed the accuracy between the surgeons. Surgeon 1 (21 patients) had no statistically significant discrepancies and was more consistent in the placement of the maxilla. Surgeon 2 had significant differences 
between predicted and actual movements and had a tendency to under advance the maxilla.

The complexity of the surgical procedure was not found to be statistically significant. However, in observing the effect of the direction of maxillary movement they compared primarily maxillary impaction verses maxillary advancements. For advancements, there was a tendency for the surgeon to not advance as much as desired. In $25 \%$ of patients, the maxilla was under advanced by $2 \mathrm{~mm}$ of more. For impaction, $30 \%$ of the cases were underimpacted by $2 \mathrm{~mm}$ or more at the posterior maxilla.

The authors conclude that many predictions had a very little discrepancy from the actual result. In fact $43 \%$ of the predictions had less than $1 \mathrm{~mm}$ average discrepancy, and $80 \%$ had less than a $2 \mathrm{~mm}$ discrepancy. Deviations from the prediction does not necessarily indicate that the result of the surgical procedure was poor, but that the surgeon might have viewed the patient's esthetic need differently ${ }^{2}$. Therefore, it may not have been a surgical error, but rather the surgeon felt a different surgical plan needed to be followed.

Semaan et al ${ }^{4}$ studied the outcomes of two surgical teams performing Le Fort I repositioning. One team was a private practice surgeon, and the other team was at a teaching hospital. Forty-two patients were consecutively treated with 22 being from private practice and 20 from a university hospital setting. This study evaluated the effect of the surgical team, effect of surgical 
complexity, and the effect of direction of the maxillary movement. There was no mention of how the maxilla was monitored during the surgery to assure surgical accuracy. Overall average discrepancy between the predicted result and actual results were found that $26 \%$ of patients were within $1 \mathrm{~mm}$ and $66 \%$ of patients were within $2 \mathrm{~mm}$ of the predicted value. The private practice surgical team had $30 \%$ within $1 \mathrm{~mm}$ and $74 \%$ within $2 \mathrm{~mm}$ of predicted outcome. The university team had $22 \%$ within $1 \mathrm{~mm}$ and $50 \%$ with $2 \mathrm{~mm}$ of the predicted outcome.

In assessing the surgical complexity they compared maxillary only surgery to maxillary and mandibular surgery. They found increased deviation from predicted for the double jaw surgery at two points: palatal plane and vertical change of maxilla. Regarding the palatal plane measurement, the surgical teams tended to over rotate the maxilla if a clockwise rotation was predicted, and under rotate the maxilla if a counter-clockwise rotation was predicted $^{4}$.

Sharifi et al ${ }^{36}$ compared forty-six patients where twenty-two had maxillary advancements only and twenty-four had maxillary advancements and mandibular setbacks. The purpose of the study was to evaluate the accuracy of model surgery prediction after orthognathic surgery and to identify possible errors associated with the prediction process ${ }^{36}$. They found accurate impaction of the maxilla within $2 \mathrm{~mm} 50 \%$ for single jaw and $58 \%$ of the double jaw 
patients. The maxilla was under-advanced in about one-third of the total cases.

In the discussion, the author described reasons for errors in the accuracy of the surgery. This article did not investigate the clinical significance of the mismatch between model prediction and actual surgical change, but it did prove its existence and highlight ways of improving orthognathic model surgery ${ }^{36}$. When using a conventional articulator for orthognathic surgery, it is essential that the angle between the occlusal plane and the Frankfort horizontal plane for the patient is the same as the angle between the occlusal plane and the upper member of the articulator on the maxillary mode ${ }^{36}$. If this is incorrect, the result of model surgery is erroneous. ${ }^{36}$ Bailey and Nowlin ${ }^{37}$ measured the angulation of the occlusal plane to the Frankfort horizontal on the Hanau articulator and compared this with lateral cephalograms: they found a mean difference of five degrees, which corresponded to a $70 \%$ error $^{37}$.

Therefore, there is a need for a common horizontal reference line from patient to radiograph to articulator to surgery ${ }^{6}$. The other source of error is the difference in the patient's mandibular position when supine and upright; the mandible tends to be positioned more posteriorly when the patients is lying down and the mouth has been actively closed into the relaxed position of centric occlusion ${ }^{36}$. 
Usually, the accuracy of a maxillary osteotomy is related to preoperative model surgery and intraoperative positional control of the maxilla. Even though the model surgery may have been carried out accurately, it is difficult to determine whether planned preoperative movements can be reproduced in the operating room ${ }^{38}$. Kwon et $\mathrm{al}^{38}$ reported the use of a facebow/bite-fork system to reposition the maxilla transoperatively. Once the maxilla was downfractured the bitefork was wired to the maxilla and earplugs and nasion adaptor were assembled to reproduce the model surgery position of the maxilla. As soon as, all bony interferences were removed and the facebow fit passively in the ear canals and on nasion, the maxilla was rigidly fixed. Their results showed a poor correlation between planned and actual movements of the maxilla. In more than $45 \%$ of cases, surgical results differed from the predicted results by more than $2 \mathrm{~mm}$.

Choi et al ${ }^{35}$ studied fifty-two Korean Class III skeletal patterns. This study used one surgeon and one skeletal pattern (Class III) to eliminate bias. Every case was a two jaw surgery. Choi ${ }^{35}$ summarized the difficulties of orthognathic surgery by saying "despite good surgical technique, in cases of complex two-jaw surgery, anatomomic obstacles, errors in mounting, model surgery and intermediate splint fabrications, unintended malpositioning of the mandibular condyle, and mistakes in measurement of the external and internal reference point in the operative procedure can make a significant discrepancy in the maxillary repositioning between the STO and surgical result". 
To measure the posterior and anterior vertical dimension of the maxilla during surgery, the distances from the midpalpebral fissure to the surgical wire of the upper first molar and from the nasion screw to the surgical wire of the upper central incisor were used ${ }^{35}$. For the anterior vertical dimension, a fixed landmark such as a nasion screw gives a stable result. However, the posterior landmark such as the midpalpebral fissure is movable, giving an unstable result. They summarized that since there is an anteroposterior movement of the maxilla along with the vertical movement in cases it is difficult to measure the change in the vertical dimension exactly. Horizontal and transverse movements of the maxilla were controlled with intermediate surgical wafers. They defined a successful surgery as a result within $1 \mathrm{~mm}$ of the prediction tracing. For maxillary advancement their accuracy rate was $87.5 \%$, maxillary setback $69.2 \%$, maxillary impaction $69 \%$, and maxillary downfracture $83.3 \%$. They concluded that to guarantee precise positioning of the maxilla, a reliable and accurate method to measure the vertical and sagittal movement of the posterior maxilla is needed ${ }^{35}$.

Ferguson and luyk investigated the accuracy of vertical repositioning of the maxilla in 45 patients, they did a comparison study to assess the reproducibility of the traditional internal reference lines and the external reference points consisting of bone screws placed at the Nasion. The results of their study confirmed that a fixed reference point at Nasion combined with 
careful and accurate surgical technique would allow accurate control of vertical position during maxillary surgery.

Gil et $\mathrm{al}^{10}$ provided a new technique to monitor the position of the maxilla intra-operatively and did a retrospective study to evaluate the surgical accuracy. The basis of the technique is the use of two fixed points, one above the Le Fort I osteotomy and one at the intact mandible to help reposition the maxilla. These points maintain the vertical distance between the skull base and the mandible, simulating the function of the incisal pin in the mock surgery ${ }^{10}$.

\section{Orthodontic Prediction Tracing}

The desire to improve facial appearance is a strong motivating factor in seeking treatment. Therefore, the ability to predict treatment outcome is essential ${ }^{31}$. Visual treatment objectives are developed from the lateral cephalometric radiograph tracing with all the data obtained from the systematic patient evaluation. ${ }^{9}$ As a communicative and diagnostic tool, the visual treatment objective can provide the surgeon and orthodontist with information about the amount and direction of the surgical movement of the hard tissue, resulting change of the soft tissue profile, and preoperative and postoperative orthodontic treatment plan ${ }^{9}$.

The presurgical position of the teeth dictates the surgical movement of the jaws and, ultimately, the soft tissue facial balance. Correct planning of 
orthodontic tooth positioning before surgery and accurate execution of the presurgical orthodontic plan enhance the surgical esthetic result. Friede et al found that the most complex surgical procedures were also the most difficult to predict and concluded that the usefulness of VTOs depends on the clinical ability to follow detailed planning. To achieve accuracy, the presurgical prediction tracing superimposes precisely on the post-surgical cephalometric radiograph $^{6}$.

The VTO is an excellent tool to communicate with patients regarding potential esthetic outcomes. However, the question still arises of the accuracy of these prediction methods and the accuracy of the surgeon manipulating the jaws in the operating room.

\section{Model Surgery}

The accuracy of orthognathic surgery depends on two main steps: paper

surgery to model surgery and model surgery to real surgery ${ }^{36,38}$. Model surgery planning on dental casts is used for the final correction of facial deformity and malocclusion. Analysis of the model surgery allows the transfer of the planned three-dimensional movements for the surgical correction of complex dentofacial deformities ${ }^{36}$. Model surgery depends on the accuracy of the recording of the dental occlusion in the correct centric relation record and the face bow transfer to the articulator. 
Ellis et $\mathrm{al}^{39_{i}}$ introduced a form of model surgery in which an intermediate splint is fabricated to help reposition the maxilla in the horizontal and transverse planes. Comparing the model surgery to the real surgical result is important because it evaluates the accuracy of the surgeon during the LeFort I procedure.

\section{Four Faces of Orthognathic Surgery ${ }^{\circledR}$ and the Tridimensional Orthognathic Gauge(TOG ${ }^{\mathrm{TM}}$ )}

The Four Faces of Orthognathic Surgery® was developed by Dr. Tim Tremont and is a comprehensive method for attaining accuracy in orthognathic surgery ${ }^{6}$. This method consists of three preoperative planning stages: clinical evaluation (Clinical Face), cephalometric prediction tracing (Cephalometric Face), model surgery (Articulator Face) and the final intraoperative stage (Surgical Face $)^{6}$. This method is based on defining the transverse facial plane by a laser. The laser projects the horizontal plane of the earth onto a patient in an upright head position. This plane is accurately transferred to each stage of the Four Faces. The goal is to have the presurgical prediction accurately superimpose on the post-surgical cephalograph. Dr. Tim Tremont reports this method to be consistently accurate within $1 \mathrm{~mm}$ of the desired jaw movement ${ }^{6}$.

During the surgical records, the patient is instructed to stand in an upright head position both in profile and frontal view as determined by two different practitioners. Once in natural upright head position, the patient's lateral poles of both condyles are marked bilaterally with black dots. A third reference 
point on the patient's right zygoma is used to define the transverse plane. This point is established by projecting a self-leveling laser that represents the true horizontal plane of the earth projected onto the patient ${ }^{6}$.

A facia facebow transfer is utilized to record the transverse, sagittal, and facial planes of the maxillary cast to the articulator. The transverse facial plane is then transferred from the articulator mounted maxillary cast to the cephalometric tracing. A common posterior landmark is identified on both the radiograph and the articulator models( often the mesiobuccal cusp of the first molar). Using a height gauge, the height difference between incision and the mesiobuccal cusp of the articulator models are measured and recorded. Through the aid of a compass, an arc is drawn from the posterior landmark at a radius equal to the height difference ${ }^{6}$. A line is drawn through the tip of incision and tangent to the $\operatorname{arc}^{6}$. This line represents the transverse facial plane. A frontal plane is established by dropping a line perpendicular to the transverse plane through incision. This creates an XY coordinate system that enables measurement of linear distances of incision point from the horizontal and vertical reference lines. The TOG ${ }^{\mathrm{TM}}$ is a measuring device that can target and verify the desired position of the maxillary teeth (jaw) precisely in all three dimensions during orthognathic surgery. ${ }^{6}$ It is an integral part of the Four Faces of Orthognathic Surgery. 


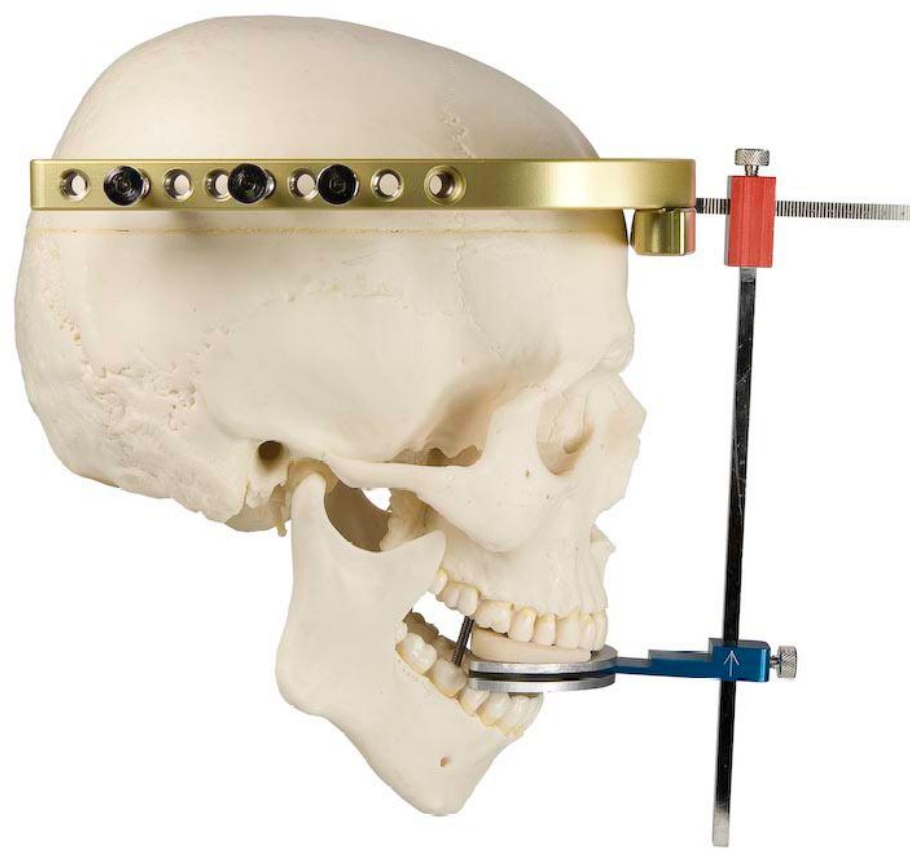

Figure 1 Tridimensional Orthognathic Gauge 


\section{Chapter III: Materials and Methods}

\section{Sample Description}

\section{Experimental Group:}

The experimental group was composed of 48 (31-hospital setting, 17private practice) consecutively treated patients treated with a Le Fort I osteotomy by both the Oral Maxillofacial Surgery team at West Virginia University and the private practice of Timothy Tremont White Oak, PA. The following inclusion criterion was used to obtain the sample: each subject received a Le Fort I maxillary osteotomy procedure, a prediction tracing was utilized, acceptable quality radiographs for both timepoints, and the Four Faces of Orthognathic Surgery ${ }^{\circledR}$ and the Tridimensional Orthognathic Gauge $\left(T O G^{\mathrm{TM}}\right.$ ) were used for the procedure. Exclusion criteria included: incomplete records, presence of a severe congenital craniofacial anomaly or syndrome, presence of any significant skeletal asymmetries, radiographs taken and not of acceptable quality. The final sample size was reduced to 32 (17-private practice, 15hospital setting) patients after ruling out patients who did not meet the criteria. Lateral cephalographs were taken prior to the orthognathic procedure (T1), and within six weeks of splint removal or removal of intermaxillary fixation (T2). 


\begin{tabular}{|l|l|}
\hline T1 & Pre-surgical treatment (Prediction tracing) \\
\hline T2 & Post-surgical treatment \\
\hline
\end{tabular}

\section{IRB Approval}

IRB exemption was obtained from West Virginia University prior to beginning this study (Appendix A) Approval was also obtained from Dr. Timothy Tremont. (Appendix B)

\section{Cephalometric Tracing}

Lateral Cephalograms were obtained from the office of Dr. Timothy Tremont and West Virginia University for the experimental group. The time points obtained were Pre-Surgical and Post-Surgical radiographs. For the film based radiographs from Dr. Tremont and the West Virginia University group, it was imperative to use the original radiographs and prediction tracing to ensure there were no magnifications errors.

The digital radiographs were downloaded in a jpeg format, and then digitized in Dolphin Imaging (Dolphin Imaging, Chatsworth, CA) for initial landmark identification and to adjust for magnification. Each image was then 
printed 1:1 to ensure there was no magnification. The digital files were printed on a Kodak Color Laser Printer ESP 7250.

Tracings were made on the printouts, and final landmark identification was performed while viewing the original file. Tracings of the final sample size were performed by one operator using a Pentel $(0.5 \mathrm{~mm})$ mechanical pencil, an orthodontic protracter, and .003 inch matte cephalometric acetate tracing film (3M Unitek, Monrovia, CA). The linear cephalometric measurements were measured using a Staedtler manual caliper and recorded to the nearest 0.5 millimeter. (Refer to Fig 5.) 


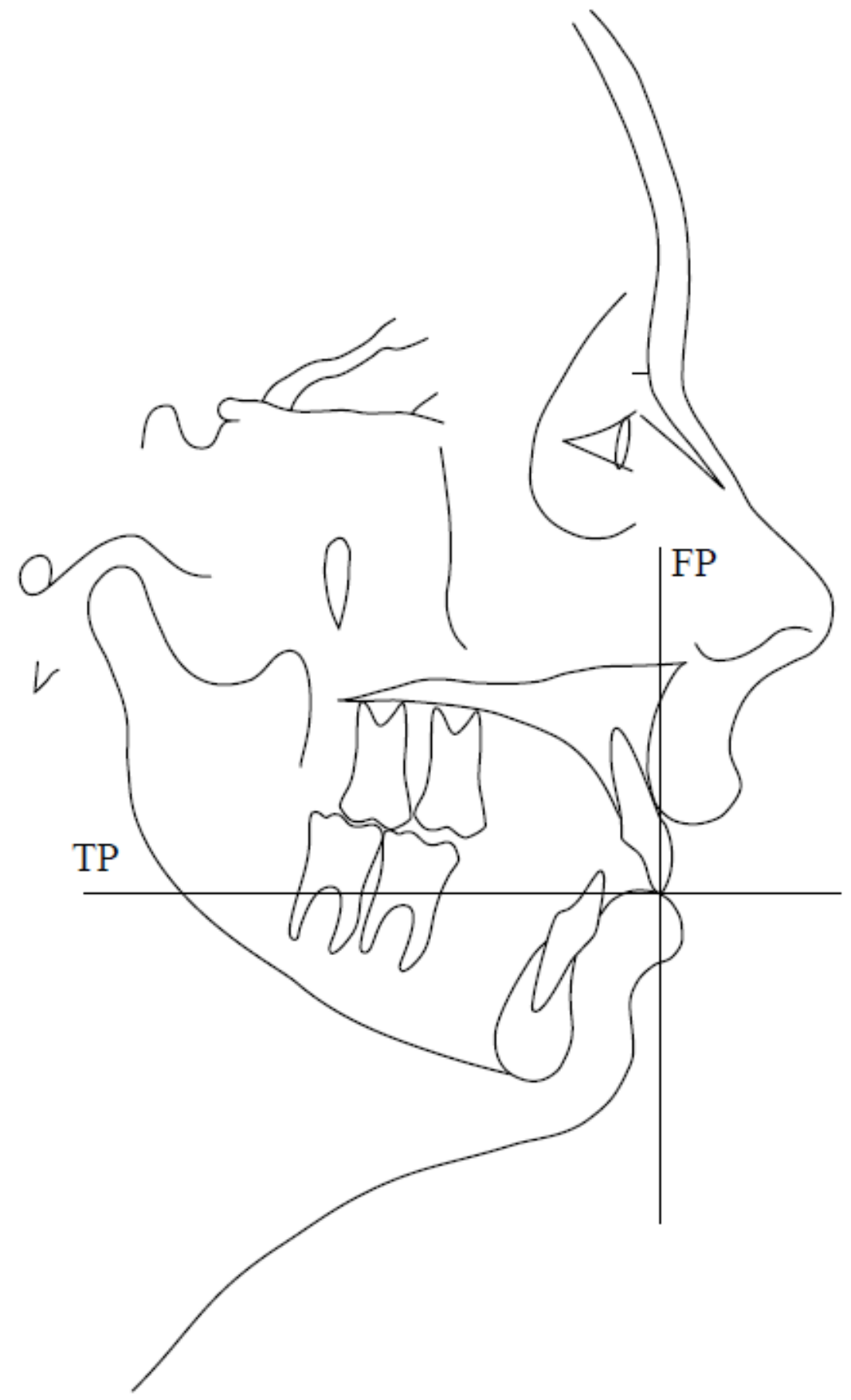

Figure 2 Pre-Surgical Cephalogram 


\begin{tabular}{|l|l|l|}
\hline Symbol & \multicolumn{1}{|c|}{ Name } & \multicolumn{1}{c|}{ Definition } \\
\hline Is (U1) & $\begin{array}{l}\text { Incision } \\
\text { superious }\end{array}$ & $\begin{array}{l}\text { The incisal point of the most prominent } \\
\text { maxillary central incisor. This point is measured } \\
\text { in the vertical and antero-posterior dimensions }\end{array}$ \\
\hline Msc & $\begin{array}{l}\text { Molar superious } \\
\text { mesial cusp }\end{array}$ & $\begin{array}{l}\text { The mesio-buccal cusp tip of the maxillary first } \\
\text { molar }\end{array}$ \\
\hline TP & $\begin{array}{l}\text { Transverse } \\
\text { Plane }\end{array}$ & $\begin{array}{l}\text { Is an imaginary plane that divides the body into } \\
\text { superior and inferior parts. It is perpendicular to } \\
\text { the coronal and sagittal planes. }\end{array}$ \\
\hline FP & Frontal Plane & $\begin{array}{l}\text { A line drawn perpendicular to the transverse } \\
\text { plane }\end{array}$ \\
\hline
\end{tabular}




\begin{tabular}{|c|c|c|}
\hline $\mathrm{Ba}$ & Basion & $\begin{array}{l}\text { the anterior margin of the foramen mangnum. The } \\
\text { midpoint of the curvature between upper and lower } \\
\text { surfaces of the basilar portion of the occipital bone }\end{array}$ \\
\hline $\mathrm{Na}$ & Nasion & $\begin{array}{l}\text { the junction of the nasal and frontal bones at the } \\
\text { most posterior point on the curvature of the bridge of } \\
\text { the nose }\end{array}$ \\
\hline $\mathrm{KR}$ & Key Ridges & $\begin{array}{l}\text { the posterior vertical portion and inferior curvature of } \\
\text { the left and right zygomatic bones }\end{array}$ \\
\hline PTM & $\begin{array}{l}\text { Pterygomaxillary } \\
\text { Fissure }\end{array}$ & $\begin{array}{l}\text { the point at the base of the fissure where the } \\
\text { anterior and posterior wall meet }\end{array}$ \\
\hline S & Sella & the center of the hypophyseal fossa (sella tursica) \\
\hline
\end{tabular}

Table 2 Skeletal Landmarks for superimposition 


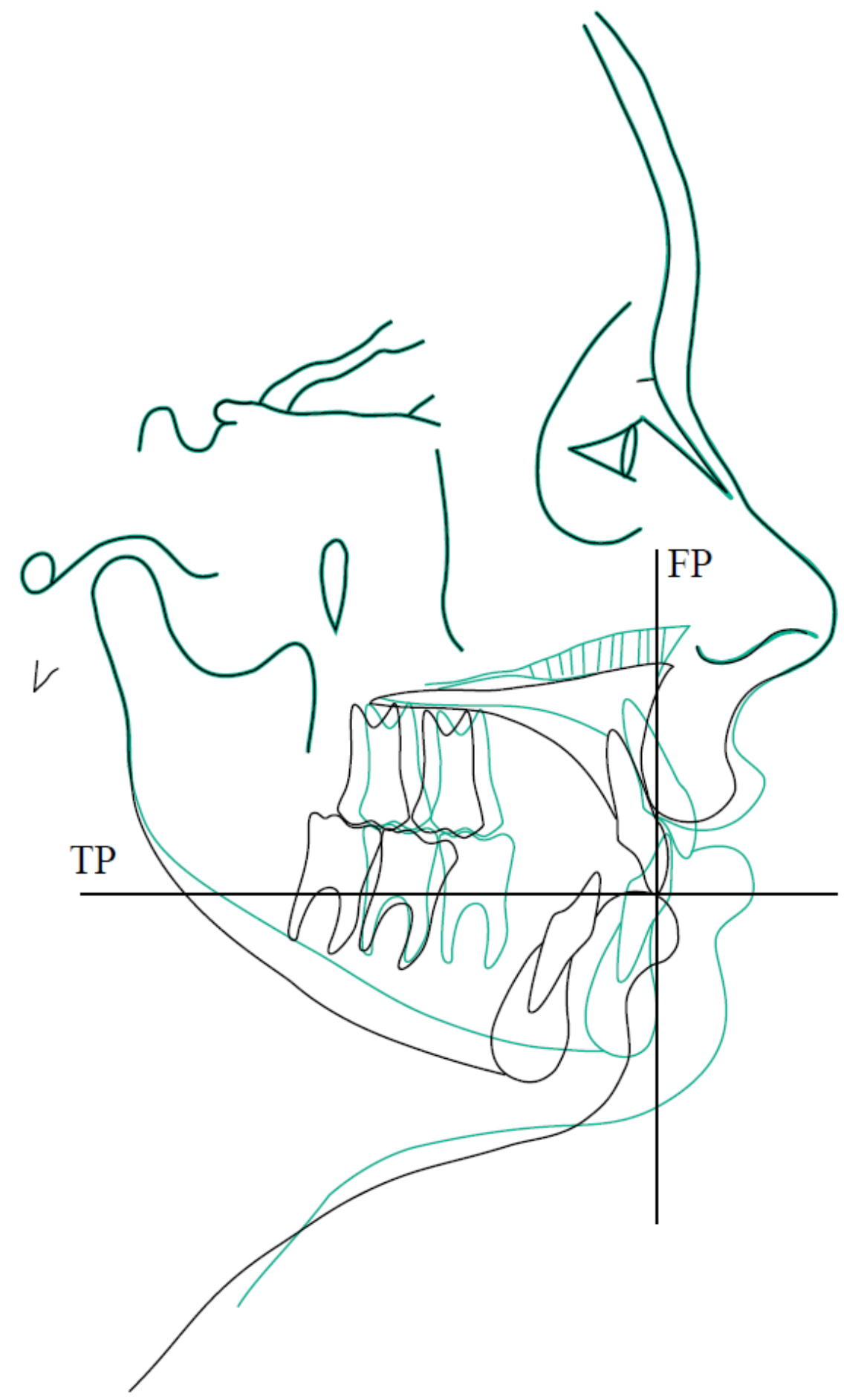

Figure 3 Prediction tracing superimposed on pre-surgical cephalogram 


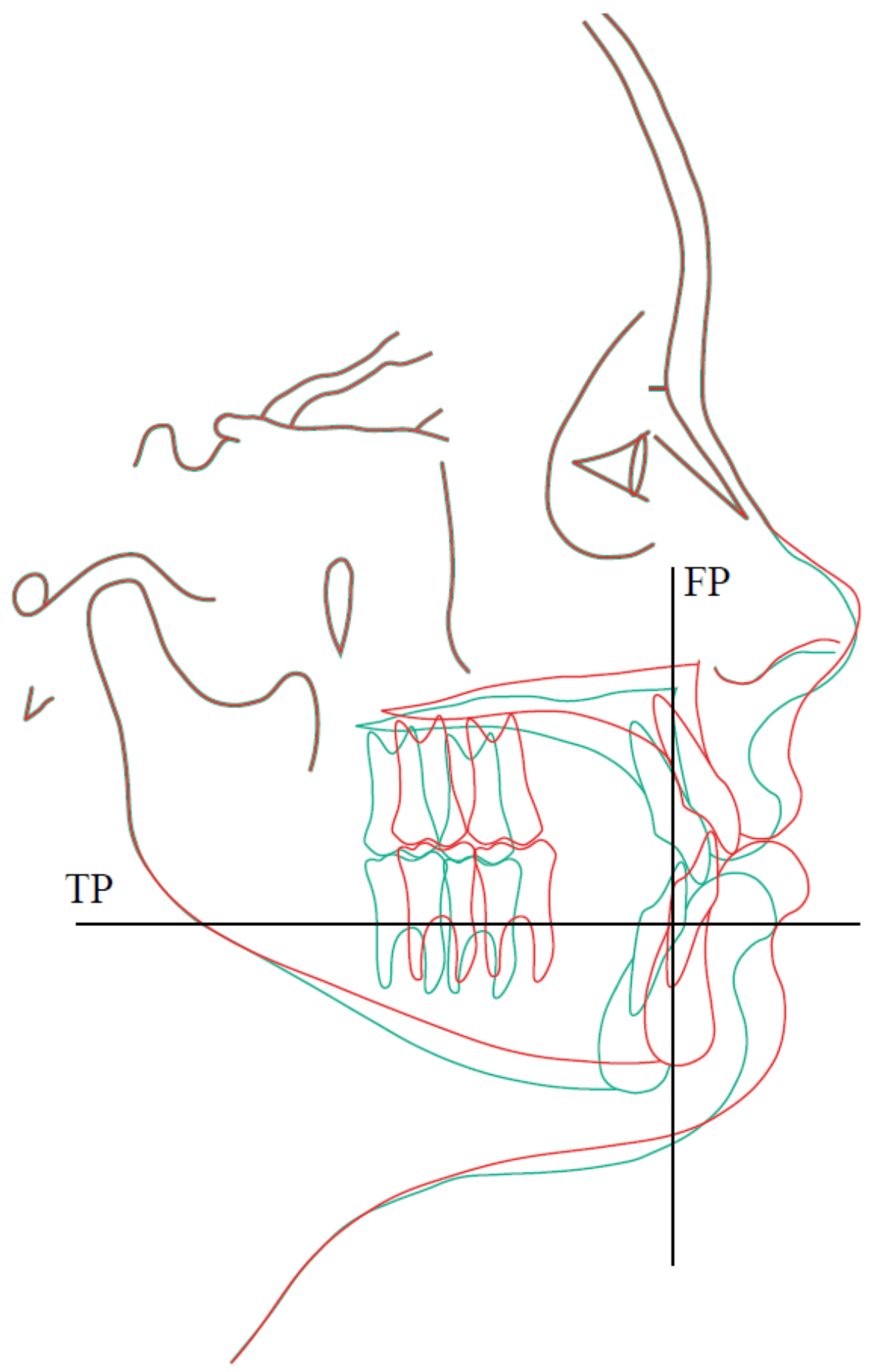

Figure 4 Prediction tracing on post-surgical cephalogram 


\section{Method to Measure Accuracy}

Pre-surgical and post-surgical cephalometric radiographs and the surgical teams' original hand generated surgical prediction tracings were collected from the sample. The two cephalograms and prediction tracing for each subject were the originals to avoid magnification errors.

The prediction tracing was overlayed on the original cephalogram and the planned vertical change to incision was measured perpendicular to the transverse plane and the planned horizontal change to incision was measured

perpendicular to the frontal plane. (Fig. 5) All measurements were made to the nearest $0.5 \mathrm{~mm}$.

The prediction tracings were then superimposed on the post-treatment cephalogram using cranial-base best fit. Six landmarks unchanged from the surgical procedure (Nasion, Sella, Basion, Pterygo-Maxillary Fissure (PFM), Key Ridge, and the Forehead) were used. The actual vertical change to incision was measured perpendicular to the transverse plane and the actual horizontal change to incision was measured perpendicular to the frontal plane (Fig. 5)

The surgical accuracy of planned horizontal and vertical changes relative to actual changes were calculated by subtracting the predicted change of incision from the actual change of incision. For vertical measurements a 
positive value indicated that the actual change to incision $\left(\Delta \mathrm{Y}_{\mathrm{A}}\right)$ was superior to the predicted change $\left(\Delta \mathrm{Y}_{\mathrm{P}}\right)$. A negative value indicated the change of incision was inferior to the planned change. For horizontal measurements a positive value indicated that the actual change to incision $\left(\Delta \mathrm{X}_{\mathrm{A}}\right)$ was anterior to the predicted change $\left(\Delta \mathrm{X}_{\mathrm{A}}\right)$. A negative value indicated that the actual change was posterior to the planned anterior-posterior change.

The overall average discrepancy between predicted and actual results was measured. The absolute values of the linear measurements were used to avoid misinterpreting the results because discrepancies in opposite directions would cancel each other out, thus giving the impression that the results were more accurate than they actually were ${ }^{4}$.

\section{Error Measurements}

The reliability of the cephalometric linear measurement was tested by evaluating the error in locating, superimposing, and measuring the differences between the planned and actual movement of incision. The prediction tracing and post-surgical radiograph of ten randomly selected patients were again superimposed two weeks after initial tracing and were analyzed to evaluate the error. An intra-rater and inter-rater test was performed to test the reliablility. 
Differences between the measurements from the first and second superimposition were compared for each.

\section{Statistical Analysis:}

The overall average discrepancy between predicted and actual results were measured. The absolute values of the linear measurements will be used to avoid misinterpreting the results because discrepancies in opposite directions would cancel each other out, thus giving the impression that results were more accurate than they actually are. The mean discrepancies, standard deviations, ranges, and $\mathrm{P}$ values for landmark locations were calculated between the surgical prediction and actual outcome. 

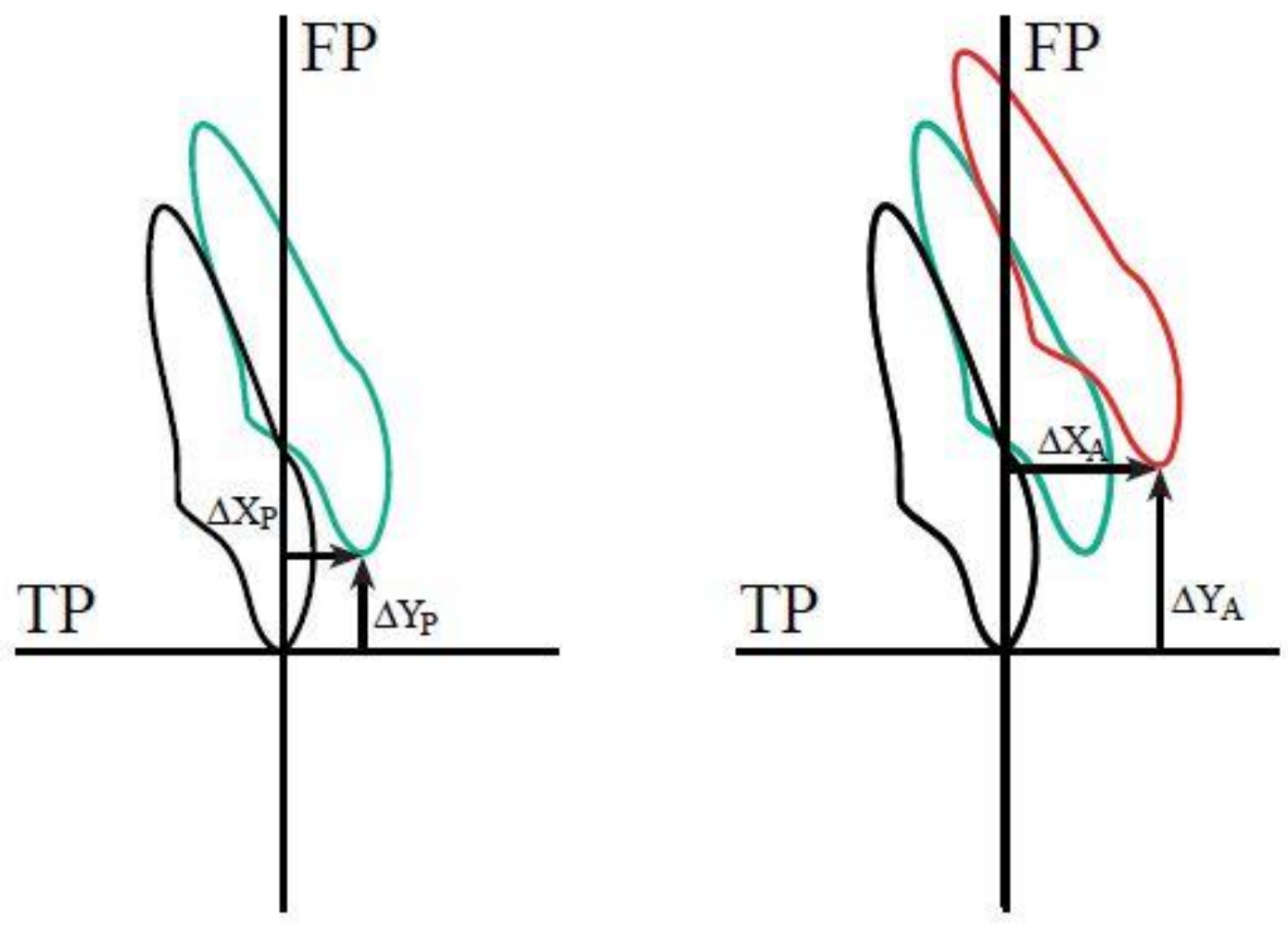

$$
\begin{aligned}
& X_{A}-X_{P}=\Delta X \\
& Y_{A}-Y_{P}=\Delta Y
\end{aligned}
$$

Figure 5 Measurement of tooth movement 


\section{Chapter IV: Results}

\section{Overall average discrepancy between predicted and actual results}

The discrepancy between the predicted results and actual results were measured. The absolute values of the linear measurements were used to avoid misinterpreting the results because discrepancies in opposite directions would cancel each other out. This would give the impression that the results are more accurate than they actually were. The data revealed that $94 \%$ of the patients were within $2 \mathrm{~mm}$ and $75 \%$ of the patients were within $1 \mathrm{~mm}$

Surgical Team

Private surgical team $(n=17)$

X-Delta

Y- Delta

Mean

$\%$ Within $1 \mathrm{~mm}$

$\%$ Within $2 \mathrm{~mm}$

$100 \%$

$100 \%$

$100 \%$

0.64

$100 \%$

$80 \%$

$53 \%$

1.00

WVU surgical team $(n=15)$

X-Delta

Y-Delta

$\begin{array}{lll}0.76 & 80 \% & 93 \% \\ 1.00 & 53 \% & 87 \%\end{array}$

\section{Table 3 Discrepancy between predicted and actual results}

Means of X-Delta and the means of Y-Delta are significantly different from zero for Private surgical team and also for WVU surgical team. 


\section{Comparison of Surgical Teams}

In order to evaluate the effect of which surgical team was used, the sample was divided into two subgroups: WVU 15 patients and private practice 17 patients. There was not a significant discrepancy between the predicted and actual outcome of incision when comparing the two teams. The mean discrepancies, standard deviations, ranges, and $\mathrm{P}$ values for incision are summarized in Table 1.

\begin{tabular}{|c|c|c|c|c|}
\hline Surgical Team & Mean & Std. dev & P-value & Range \\
\hline \multicolumn{5}{|c|}{ Private surgical team $(n=17)$} \\
\hline X-Delta & 0.50 & 0.43 & $0.0002^{*}$ & $(-1,1)$ \\
\hline Y- Delta & 0.64 & 0.38 & $<0.0001^{*}$ & $(-1,1)$ \\
\hline \multicolumn{5}{|c|}{ WVU surgical team $(n=15)$} \\
\hline X-Delta & 0.76 & 0.67 & $0.0006^{*}$ & $(-1.5,2.5)$ \\
\hline Y-Delta & 1.00 & 0.88 & $0.0006^{*}$ & $(-2,3)$ \\
\hline
\end{tabular}

\section{Table 4 Comparison of Surgical Teams}

Means of X-Delta and the means of Y-Delta are significantly different from zero for Private surgical team and also for WVU surgical team.

X-Delta

$\begin{array}{lrrr}\text { Team } & \mathrm{n} & \text { Mean } & \text { Std Dev } \\ \text { Private } & 17 & 0.50 & 0.43 \\ \text { WVU } & 15 & 0.76 & 0.67\end{array}$

\section{Table 5 Comparison of Surgical Teams X-Delta}

There is no significant difference between the means of X-Delta for WVU and Private teams $\mathrm{P}$-value $=0.18$ 
Y-Delta

Team

Private

WVU

$\begin{array}{rrr}\mathrm{n} & \text { Mean } & \text { Std Dev } \\ 17 & 0.64 & 0.38 \\ 15 & 1.00 & 0.88\end{array}$

\section{Table 6 Comparison of Surgical Teams Y-Delta}

There is no significant difference between the means of $\mathrm{Y}$ - Delta for WVU and Private teams,

$P$-value $=0.14$

\section{Effect of surgical complexity}

In order to evaluate the effect of surgical complexity on the accuracy; the sample was divided into four subgroups: maxillary surgery only, bimaxillary surgery, maxillary surgery with genioplasty, and bimaxillary with genioplasty. The sample was also divided by the complexity of the Le Fort I procedure according to how many pieces the maxilla was split.

\begin{tabular}{lccc} 
Surgical Complexity & Mean & Std. dev & P-value \\
\hline Bimax $(\mathrm{n}=17)$ & & & \\
X-Delta & 0.61 & 0.51 & $0.0001^{*}$ \\
Y-Delta & 0.79 & 0.75 & $0.0005^{*}$ \\
& & & \\
Bimax /Gen ( $\mathrm{n}=7)$ & & & \\
X-Delta & 0.78 & 0.86 & 0.051 \\
Y-Delta & 0.92 & 0.45 & $0.001^{*}$ \\
& & & \\
Max $(\mathrm{n}=7)$ & & & \\
X-Delta & 0.42 & 0.34 & $0.01^{*}$ \\
Y-Delta & 0.78 & 0.80 & $0.04^{*}$
\end{tabular}

\section{Table 7 Effect of Surgical Complexity}

For Bimaxillary and Maxillary, means of X-Delta are significantly different than zero and the mean of X-Delta for Bixmaxillary/Genioplasty is not significantly 
different from zero. The means of Y-Delta are significantly different from zero for all surgical complexities

X-Delta

Surgical complexity

Bimaxillary Surgery

n Mean

Std Dev

Bimaxillary Surgery w/ Genioplasty

17

0.61

0.51

Maxillary Surgery

$7 \quad 0.78$

0.86

$7 \quad 0.42$

0.34

Table 8 Effect of Surgical Complexity X-Delta

For X-Delta, there were no significant differences between the means of surgical complexities, P-value $=0.52$

Y-Delta

Level

Bimaxillary Surgery

n

17

Mean

0.79

Std Dev

Bimaxillary Surgery w/ Genioplasty

7

Maxillary Surgery

7

0.92

0.75

0.45

0.78

0.80

\section{Table 9 Effect of Surgical Complexity Y-Delta}

For Y-Delta, there were no significant differences between the means of surgical complexities, P-value $=0.90$. 


\section{Type of Le Fort I}

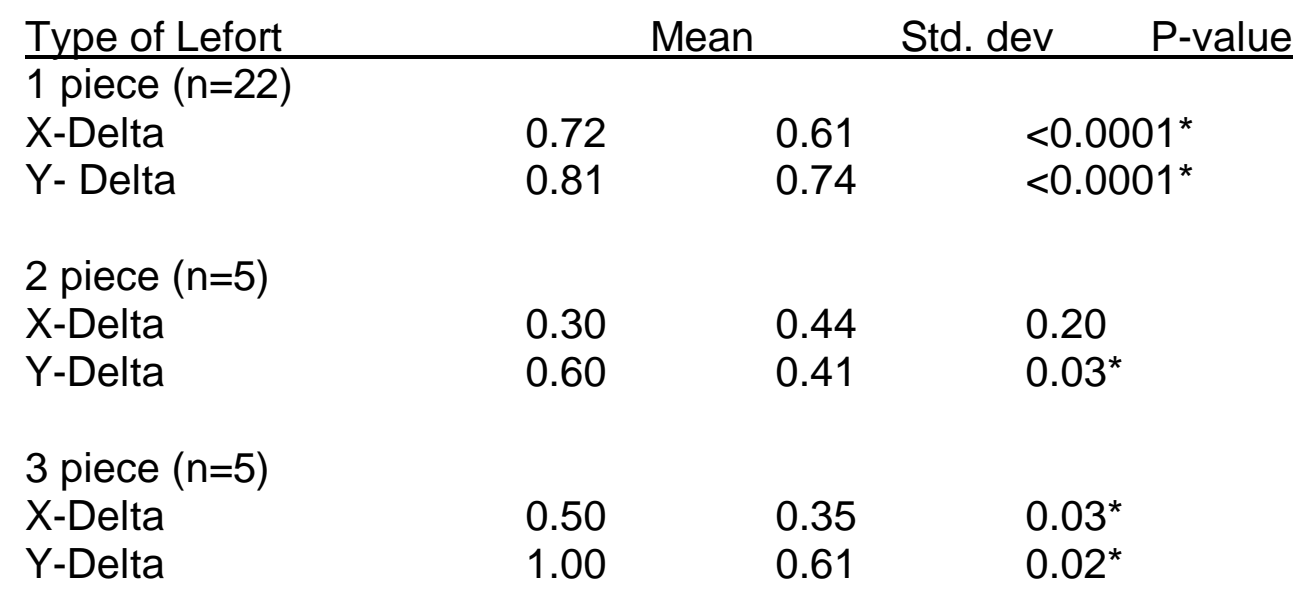

The means of X-Delta for 1-piece and 3-piece Lefort are significantly different from zero. For 2-piece Lefort the mean of X-Delta is not significantly different from zero.

For all types of Lefort, means of Y-Delta are significantly different than zero

8) Comparison of types of Lefort.

X-Delta

$\begin{array}{lrrr}\text { Type of Lefort } & \mathrm{n} & \text { Mean } & \text { Std Dev } \\ 1 \text { piece } & 22 & 0.72 & 0.61 \\ 2 \text { piece } & 5 & 0.30 & 0.44 \\ 3 \text { piece } & 5 & 0.50 & 0.35\end{array}$

For X-Delta, there is no significant difference between the means of types of Lefort, $\mathrm{P}$-value $=0.28$.

Y-Delta

$\begin{array}{lrrr}\text { Type of Lefort } & \mathrm{n} & \text { Mean } & \text { Std Dev } \\ 1 \text { piece } & 22 & 0.81 & 0.74 \\ 2 \text { piece } & 5 & 0.60 & 0.41 \\ 3 \text { piece } & 5 & 1.00 & 0.61\end{array}$

For Y-Delta, there is no significant difference between the means of types of Lefort, $\mathrm{P}$-value $=0.66$. 


\section{Effect of direction of primary maxillary movement}

To evaluate the effect of the direction of maxillary movement, the sample was divided into three subgroups: advancement $(n=10)$, advancement-

impaction (Al) ( $n=19)$, and downgraft-advancement (DA) $(n=3)$.

\begin{tabular}{llll} 
Direction & Mean & Std. dev & P-value \\
\hline A ( $n=10)$ & & & \\
X-Delta & 0.45 & 0.36 & $0.003^{*}$ \\
Y-Delta & 0.75 & 0.95 & $0.03^{*}$ \\
& & & \\
DA $(n=3)$ & & & \\
X-Delta & 0.66 & 0.28 & 0.057 \\
Y-Delta & 0.66 & 0.57 & 0.18 \\
& & & \\
IA $(n=19)$ & & & \\
X-Delta & 0.71 & 0.67 & $0.0002^{*}$ \\
Y-Delta & 0.86 & 0.54 & $<0.0001^{*}$
\end{tabular}

\section{Table 10 Effect of direction of primary maxillary movement}

For directions of $A$ and IA, the means of X-Delta and Y-Delta are significantly different from zero. For direction DA, the means of X-Delta and Y-Delta are not significantly different from zero.

X-Delta

$\begin{array}{lrrr}\text { Direction } & \mathrm{n} & \text { Mean } & \text { Std Dev } \\ \text { A } & 10 & 0.45 & 0.36 \\ \text { DA } & 3 & 0.66 & 0.28 \\ \text { IA } & 19 & 0.71 & 0.67\end{array}$

Table 11 Effect of direction of primary maxillary movement X-Delta

There are no significant differences between the X-Delta means at different directions of maxillary movement, P-value $=0.51$.

Y- Delta

Direction

A

DA

IA

$\mathrm{n}$

Mean

0.75

Std Dev

10

0.66

0.95

3

0.86

0.57

19

0.54 
Direction $\quad \mathrm{n} \quad$ Mean Std Dev

\section{Table 12 Effect of direction of primary maxillary movement Y-Delta}

There are no significant differences between the $Y$-Delta means at different directions of maxillary movement, $\mathrm{P}$-value $=0.84$

\section{Reliability of Variable Measurements}

Since one examiner made all measurements in this study an intra-rater reliability test of measurement was completed. This test was performed to determine the repeatability of superimposing the prediction tracing on the postsurgical radiograph through cranial base best fit and properly locating incision. A random sample of ten subjects had the data collection process repeated, and all measurements were completed a second time. It is important to note that this reliability test was done no sooner than two weeks after the first measurements were completed. The results showed that a reliability coefficient of 0.98 was found for the $X$ axis measurement and 0.91 for the $Y$ axis measurement.

i) X measurements: Reliability coefficient $=0.98$.

ii) $Y$ measurements: Reliability coefficient $=0.91$.

An inter-rater test was also utilized to test the reliability. The error in locating, superimposing, and measuring the changes of the different landmarks 
by two examiners was performed on radiographs of 10 subjects. If either rater was off by more than $0.5 \mathrm{~mm}$, the examiners would re-calibrate their measurements.

i) X measurements: Reliability coefficient $=0.99$.

ii) $Y$ measurements: Inter-rater reliability coefficient $=0.93$ 


\section{Chapter V: Survey on Orthognathic Surgery}

In addition to data collected from the pre-surgical and post-surgical $x$ rays the following written survey was electronically mailed to all active orthodontists who are on the American Association of Orthodontics e-mail list (Fig. 10) The data collected from the survey was intended to supplement the information gained from the study, and provide insight into the clinical practice regarding orthognathic surgery in the United States.

1) In what component of the country do you practice?
a. Northeastern
b. Great Lakes
c. Middle Atlantic
d. Southern
e. Southwestern
f. Midwestern
g. Rocky Mountain
h. Pacific Coast

2) How many years have you been practicing orthodontics?
a. Less than 5 years
b. $5-10$
C. $10-20$
d. More than 20 years 
3) What percentage of you patients would require orthognathic surgery to have an optimal dentofacial treatment outcome?
a. Less than $5 \%$
b. $5-20 \%$
c. $20-40 \%$
d. $40-60 \%$
e. Great than $60 \%$

4) How often do you discuss a surgical treatment option with patients for who orthognathic surgery would be necessary for an optimal treatment outcome?
a. Always
b. Most of the time
c. Only sometimes
d. Rarely

5) Who treatment plans the surgical movements for your orth0gnathic surgery patients?
a. Oral Surgeon
b. Orthodontist

6) Who does most of your orthognathic surgeries?
a. Private practice surgeons
b. University setting surgeons
c. Surgeons in other settings

7) Do you and/or the surgeon use a cephalometric analysis to treatment plan where to surgically reposition the jaws?
a. Yes 
b. No

8) Do you and/or surgeon routinely do a prediction tracing prior to surgery?
a. Yes
b. No

9) Do you do the model surgery with the oral surgeon?
a. Yes
b. No

10) How pleased are you with the surgical outcomes?
a. Almost always
b. Sometimes
c. Rarely

11) How pleased are your patients with the surgical outcomes?
a. Almost always
b. Sometimes
c. Rarely

12) Do you superimpose a prediction tracing on a post-operative cephalometric radiograph to evaluate the accuracy of a surgical outcome?
a. Never
b. Sometimes
c. Always

13) When patients for who a surgical treatment option would be optimal do not have the surgery, it is usually because of the following factor or factors:
a. The patient declines surgery
b. Insurance plan will not cover the surgery 
c. The risks outweigh the rewards

d. You are not confident enough with your knowledge and skills to provide surgical orthodontic treatment

e. The surgical outcomes are usually no acceptable

f. You cannot find a surgeon will to do the surgery

\section{Survey Sample Size}

The survey was electronically distributed to all active orthodontists in both private practice and academic settings. The list was compiled from the 2012-2013 American Association of Orthodontists membership directory. The number of responses collected from this survey totaled 105. Using Survey Monkey, data was analyzed to gather trends related to the involvement and satisfaction of orthodontists when orthognathic surgery is utilized. 


\section{Survey Responses}

A total of 105 responses were returned by the American Association of Orthodontists membership directory. Geographic distribution is shown as a percentage according to which constituent the orthodontist practices.

In what constituent of the country do you practice?

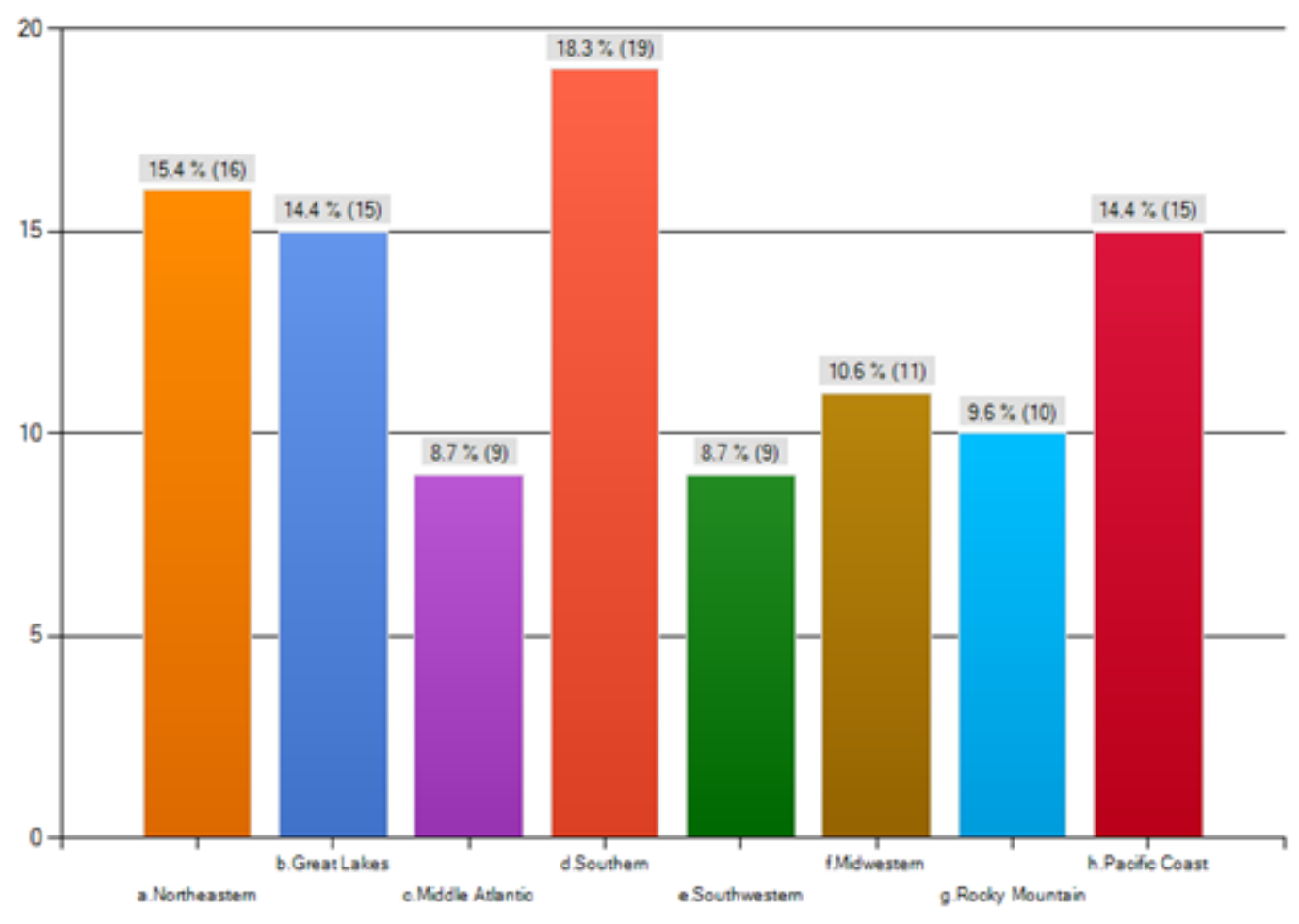

Figure 6.

Figure 6 Distribution of Practicing Orthodontics

\section{Years of Practice}


Responses to the survey related to years of practice by the following ranges: less than 5 years, $5-10$ years, $10-20$ years, and over 20 years. A breakdown of the responses in shown in Fig. 2 . The majority of the surveys that were completed were by practitioners of over 20 years.

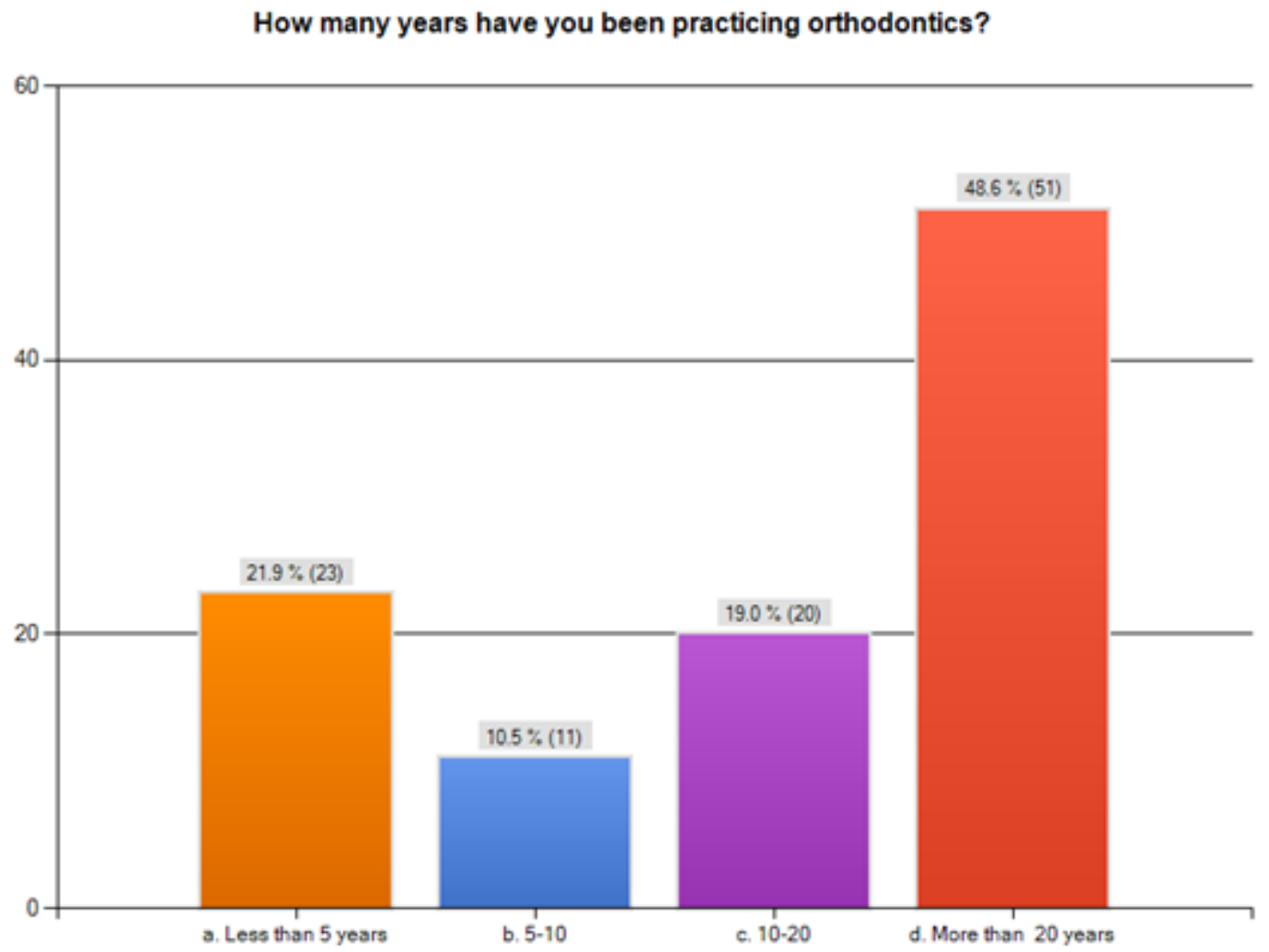

Figure 7 Survey result: Years of practice

\section{Prevalence of Orthognathic Surgery}


Responses to the survey related to the treatment philosophy and need for orthognathic surgery. The majority of orthodontists 49 (47\%) find the prevalence of surgery to be around $5-20 \%$. However, 43 (41\%) found the requirement to be less than $5 \%$. The other responses were as follows: prevalence of $20-40 \%$ was $7(7 \%)$ responses, $40-60 \%$ was $3(3 \%)$ responses, and greater than $60 \%$ was $3(3 \%)$ responses.

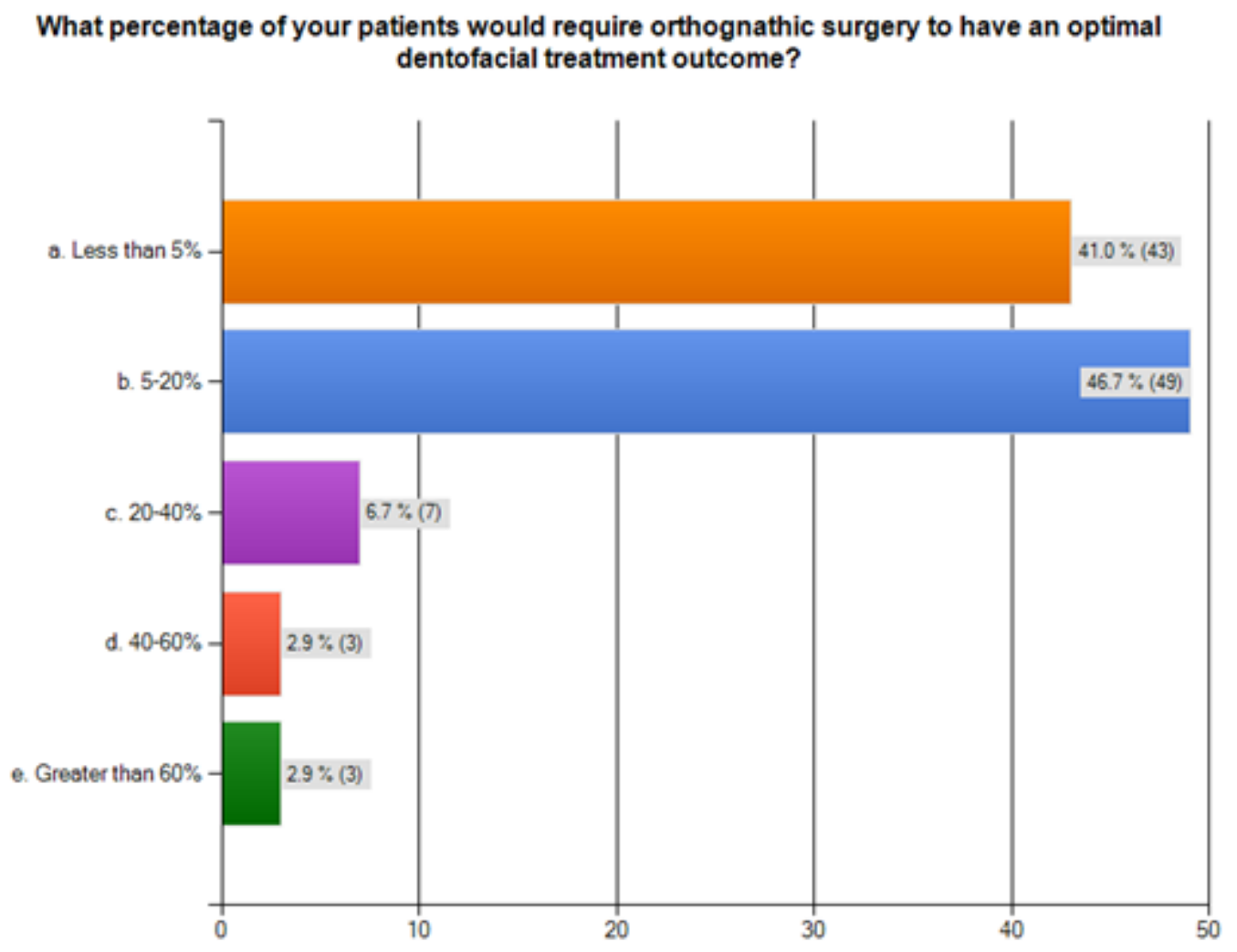

Figure 8: Survey result: Patients that would require surgery for optimal dentofacial outcome

\section{Discussion of Surgical Treatment}


Of the respondents that filled out the survey, $71(67 \%)$ inform their patients always that they are a surgical candidate. The other respondents varied from: most of the time $24(23 \%)$, only sometimes $7(7 \%)$, and rarely 3 $(2.9 \%)$.

$$
\begin{aligned}
& \text { How often do you discuss a surgical treatment option with patients for } \\
& \text { whom orthognathic surgery would be necessary for an optimal } \\
& \text { treatment outcome? }
\end{aligned}
$$

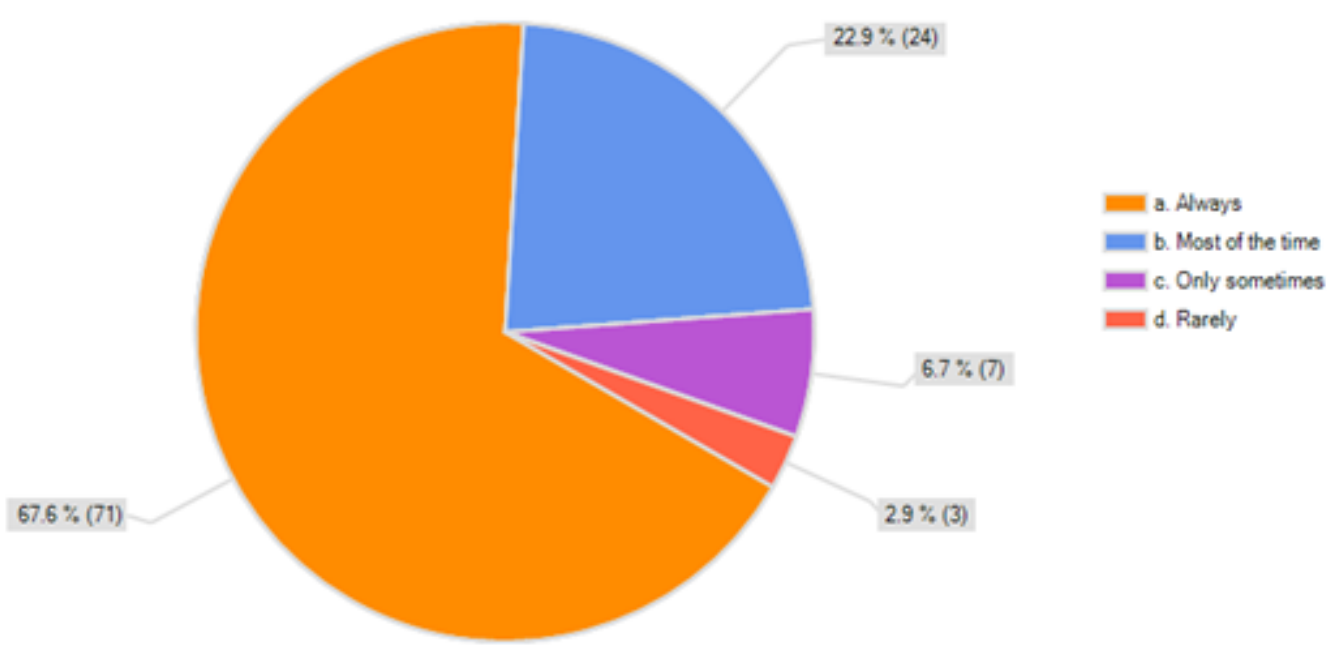

Figure 9 Survey result: Percentage of Orthodontists Discussing Need for Surgery

\section{Treatment Planning the Surgery}


Of the responses collected, $75(72 \%)$ indicated that the surgeon treatment plans the surgical movements. $29(28 \%)$ respondents indicated that the orthodontist treatment planned the surgical movements. surgery patients?

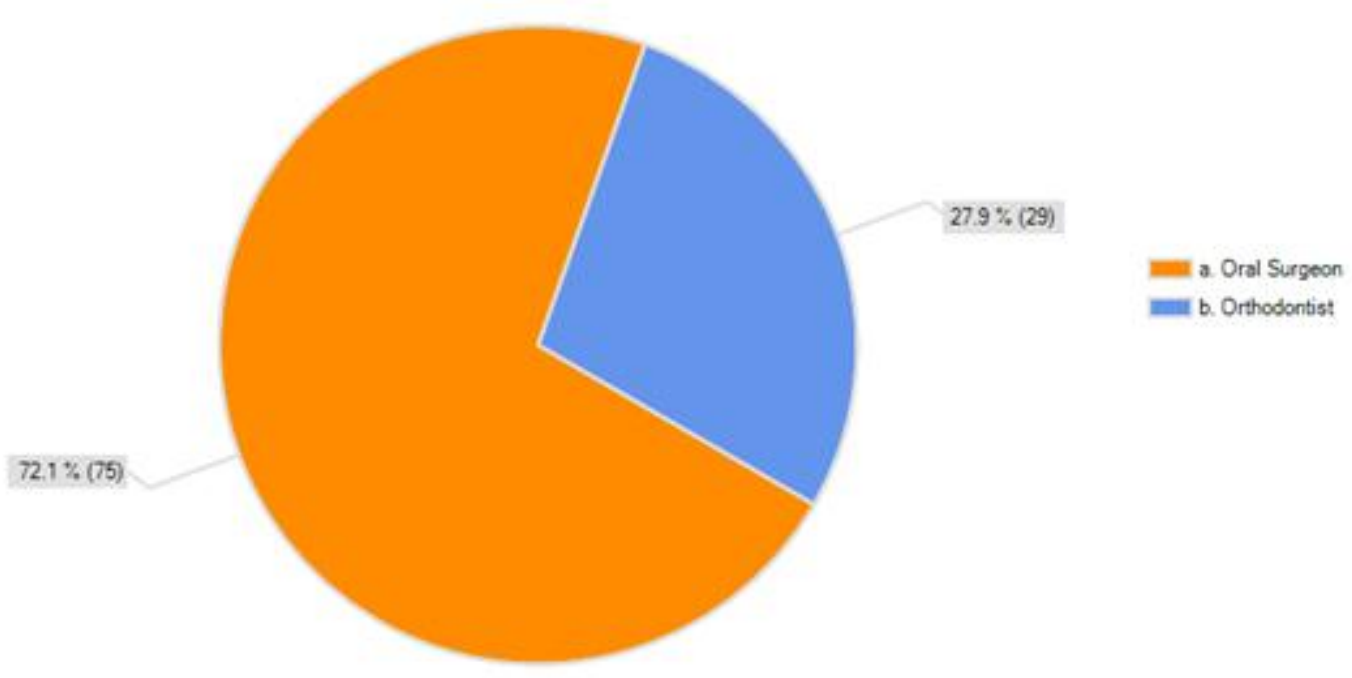

Figure 10 Survey Result: Who treatment plans the surgery

\section{Private Practice or University Setting Oral Surgeons}


Responses to the survey related to the type of surgeon that was selected. $67(64 \%)$ of the responses indicated that they prefer to work with a private practicing oral-maxillofacial surgeon. In regards to the university setting surgeons, $31(30 \%)$ indicated that they worked with these surgeons.

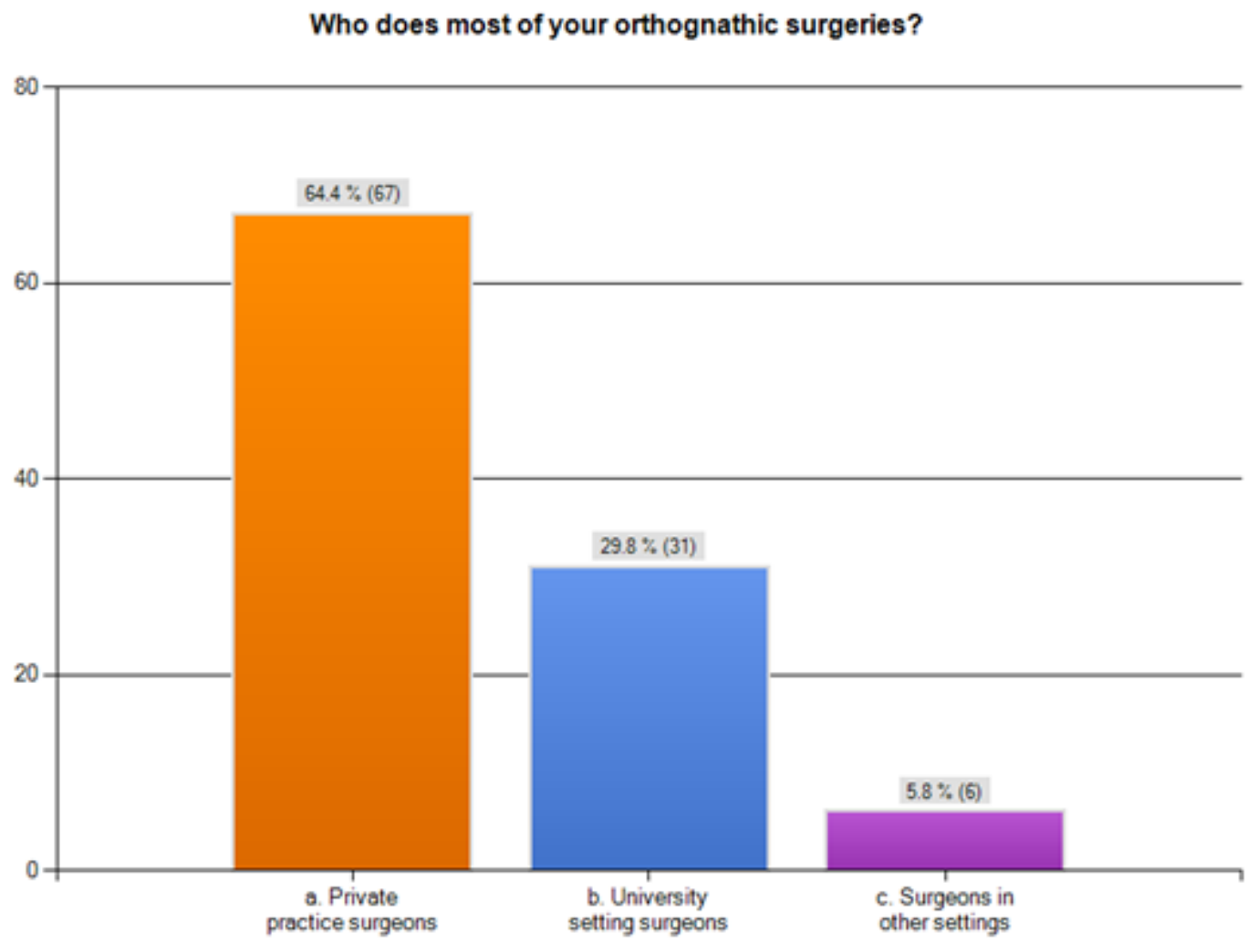

Figure 11 Survey Results: Setting in which oral surgeon practices 


\section{Cephalometric Analysis}

The majority of the responses $97(92 \%)$ indicated that the orthodontist and the oral surgeon use a cephalometric analysis to help aid in positioning the jaws. Only 8 (8\%) answered that did not use a cephalometric analysis.

Do you and/or the surgeon use a cephalometric analysis to treatment plan where to surgically reposition the jaws?

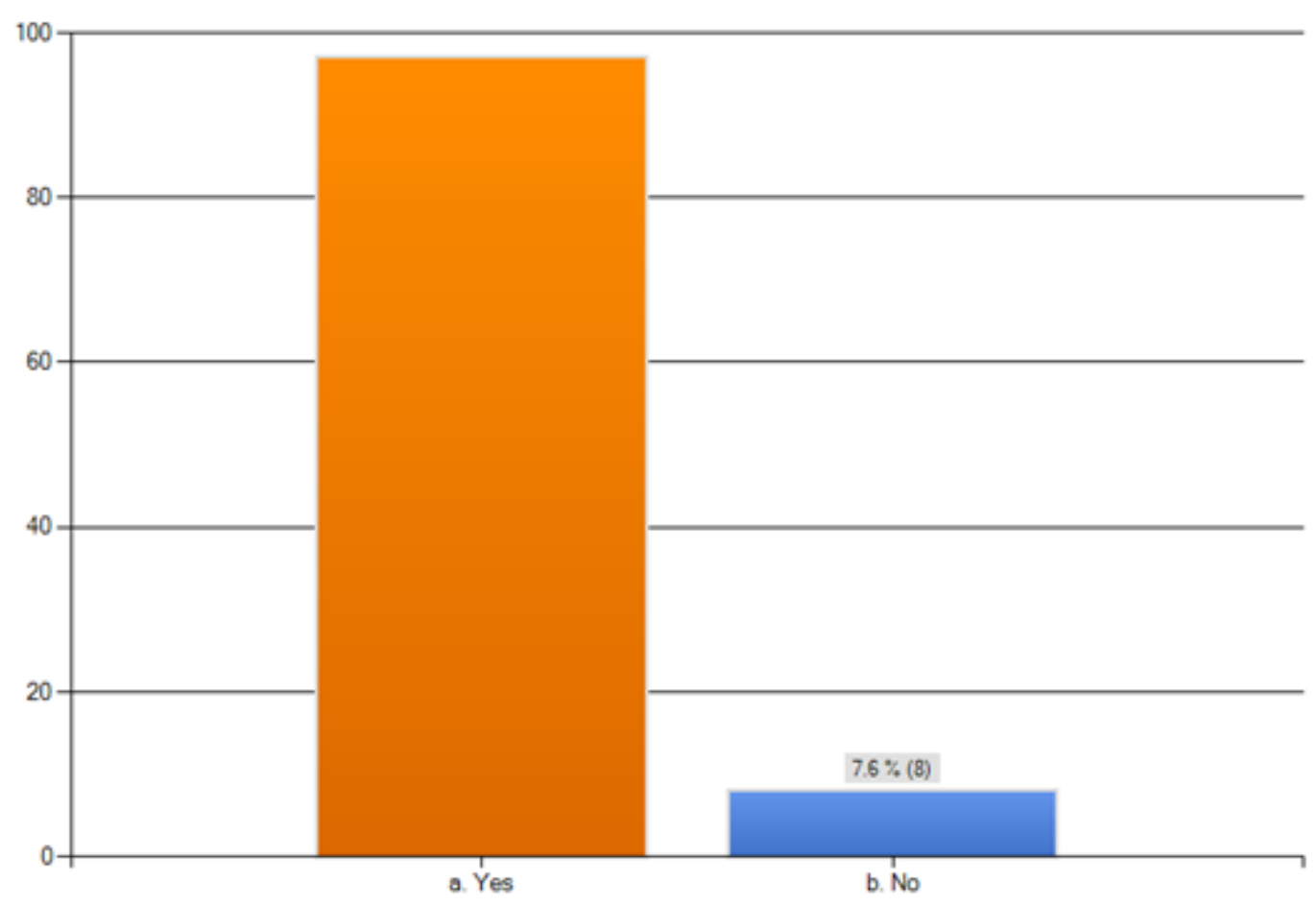

Figure 12 Survey Results: Percentage that use cephalometric analysis to treatment plan 


\section{Prediction Tracing}

The majority of the respondents utilized a prediction tracing $69(64 \%)$ to set visual goals for the procedure. Of the responses 34(33\%) answered no that they do not utilize a prediction tracing prior to surgery.

Do you and/or the surgeon routinely do a prediction tracing prior to surgery?

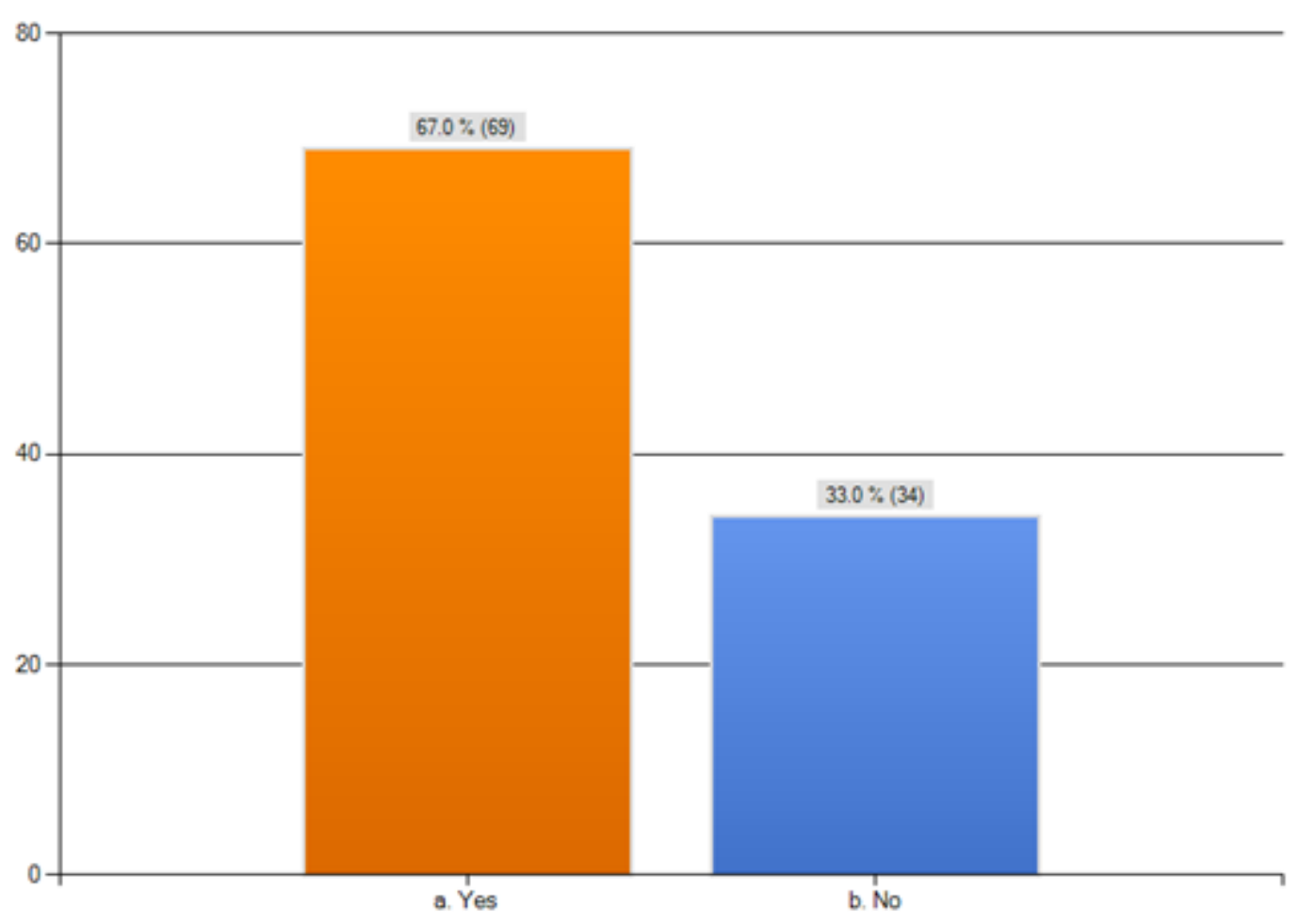

Figure 13 Survey Result: Percentage of orthodontists that use a prediction tracing 


\section{Model Surgery}

Over half of the respondents do not participate in the model surgery with the oral surgeon $61(58.7 \%) .43(41 \%)$ of the responses reported participating in the model surgery with oral surgeon.

Do you do the model surgery with the oral surgeon?

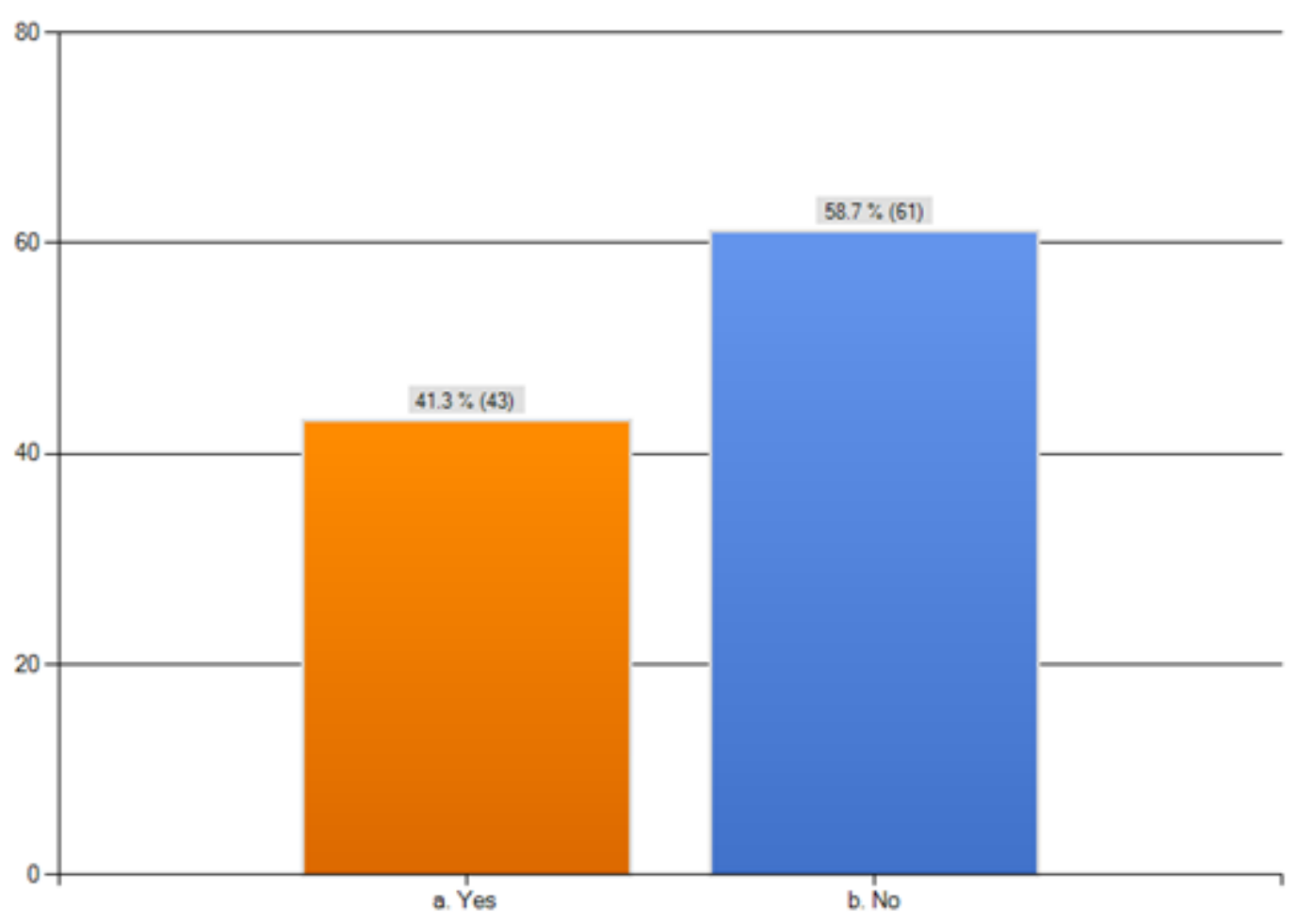

Figure 14 Survey Results: Who does the model surgery 


\section{Orthodontists Assessment on Outcomes}

The majority of the respondents were pleased with the surgical outcomes $82(81 \%)$. Only $2(2 \%)$ were rarely pleased with the surgical outcomes. 17 (17\%) were sometimes pleased with the surgical outcomes.

How pleased are you with the surgical outcomes?

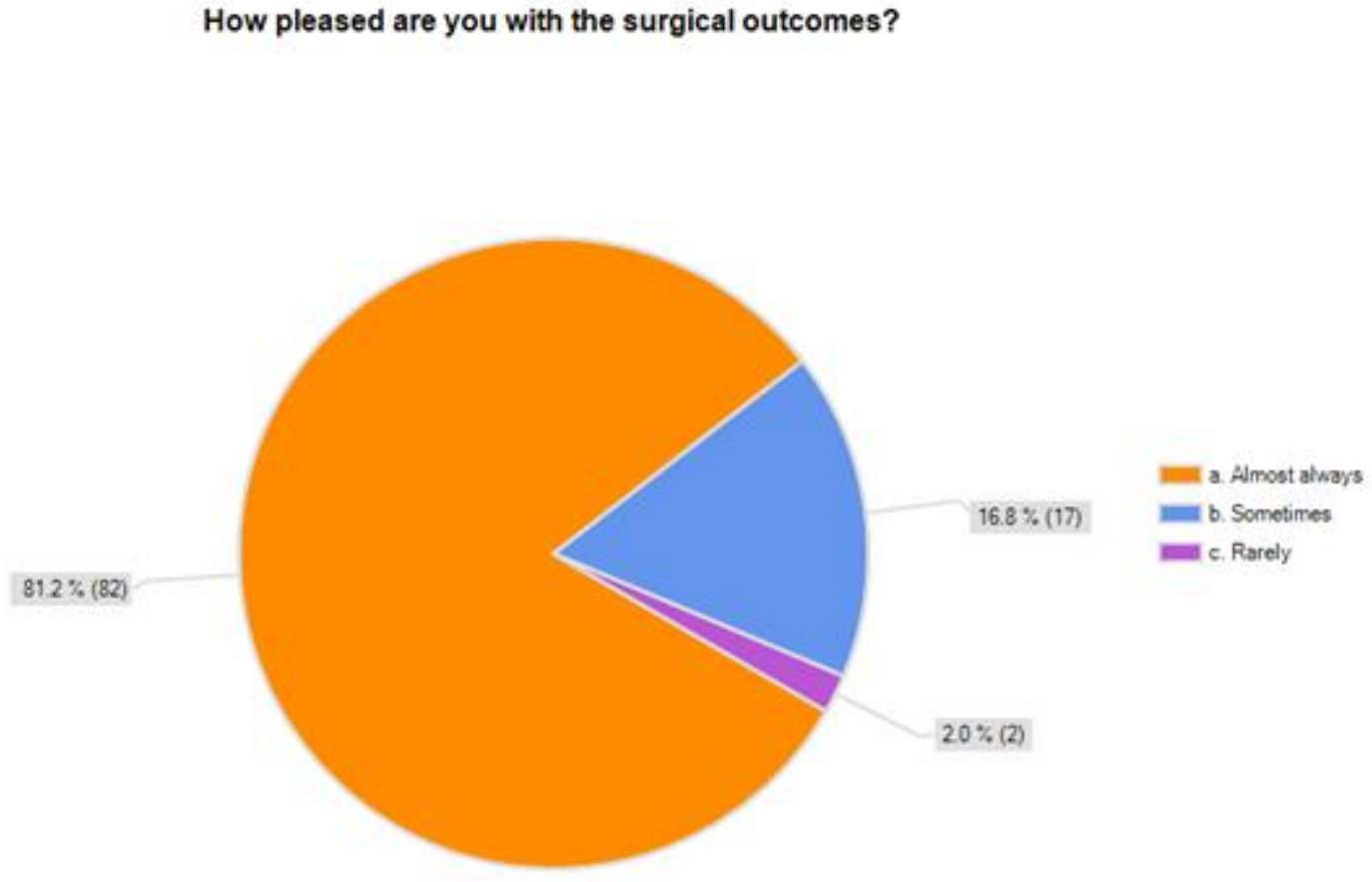

Figure 15 Survey Results: Orthodontists assessment on surgical outcomes 


\section{Patient Assessment on Outcomes}

Responses to the survey related to a predominant conclusion that patients are almost always pleased with the surgical outcome 95 (91\%). The other responses were sometimes $8(8 \%)$ and rarely $2(2 \%)$

How pleased are your patients with the surgical outcomes?

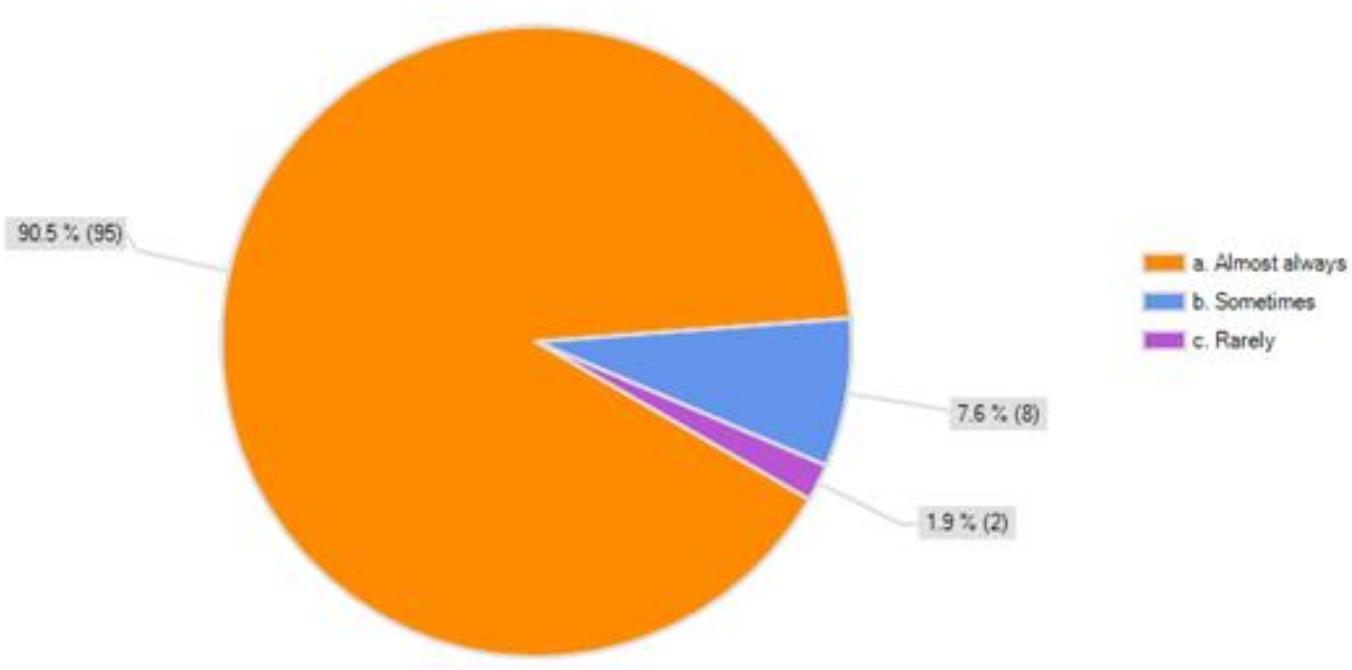

Figure 16 Survey Results: Patients assessment on surgical outcomes 


\section{Superimposition of Prediction Tracing}

Responses to the survey related to how often the practicing orthodontist does a post-operative superimposition to evaluate the accuracy of the surgical outcome. Only $14(14 \%)$ always do a superimposition on the prediction tracing. The other responses were: sometimes 54 (54\%), and never 37 (35\%).

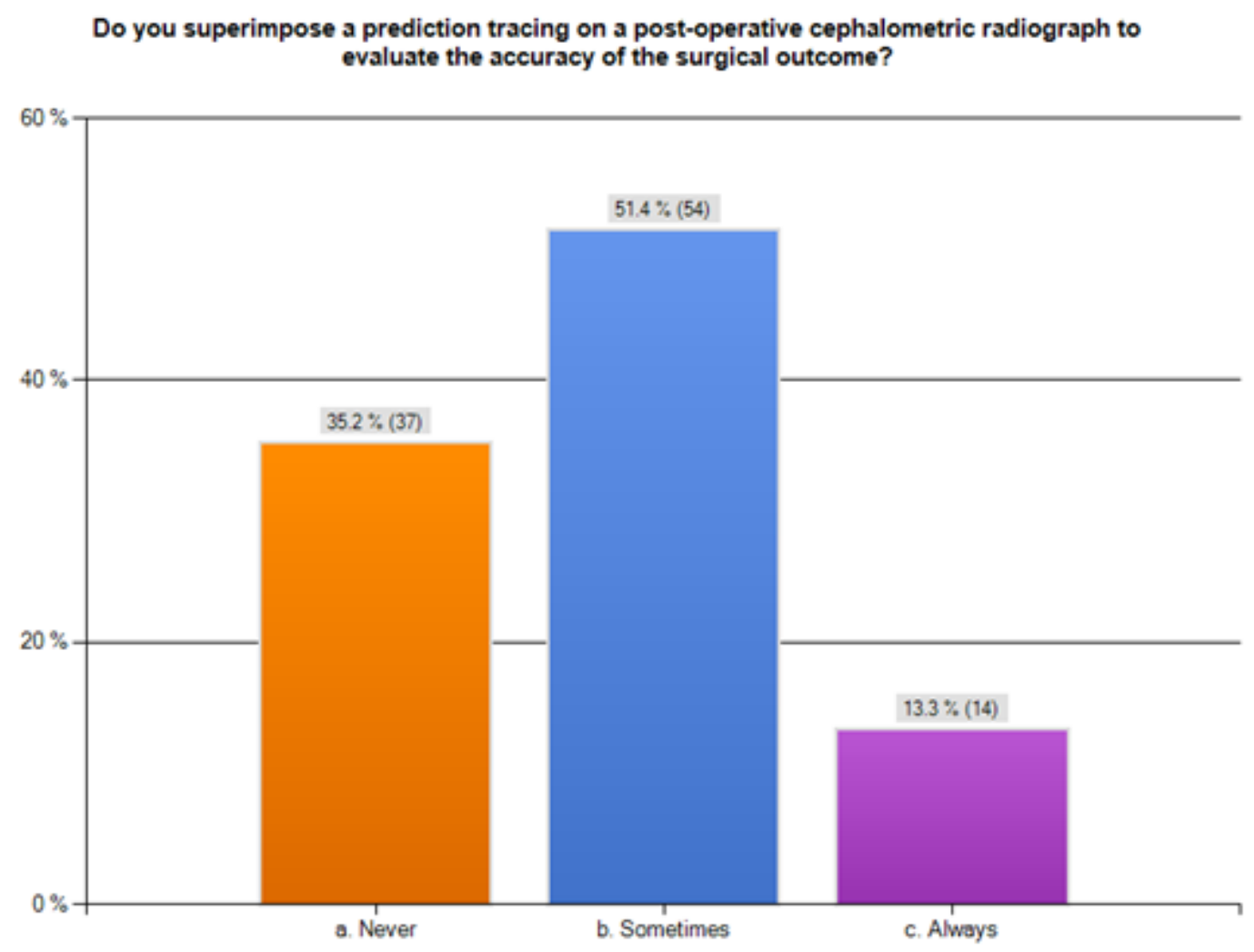

Figure 17 Survey Results: Percentage superimposition of prediction tracing 


\section{Reasons for Declining Surgery}

Responses to the survey related to why a surgery is either not performed or declined. The majority of responses 91 (87\%) answered that the patient declines surgery. $70(67 \%)$ respondents thought the reason the surgery was void was because the insurance plan does not cover the surgery. 27 (26\%) respondents that the risk outweighed the rewards.

When patients for whom a surgical treatment option would be optimal do not have the surgery, it is usually because of the following factor or factors:

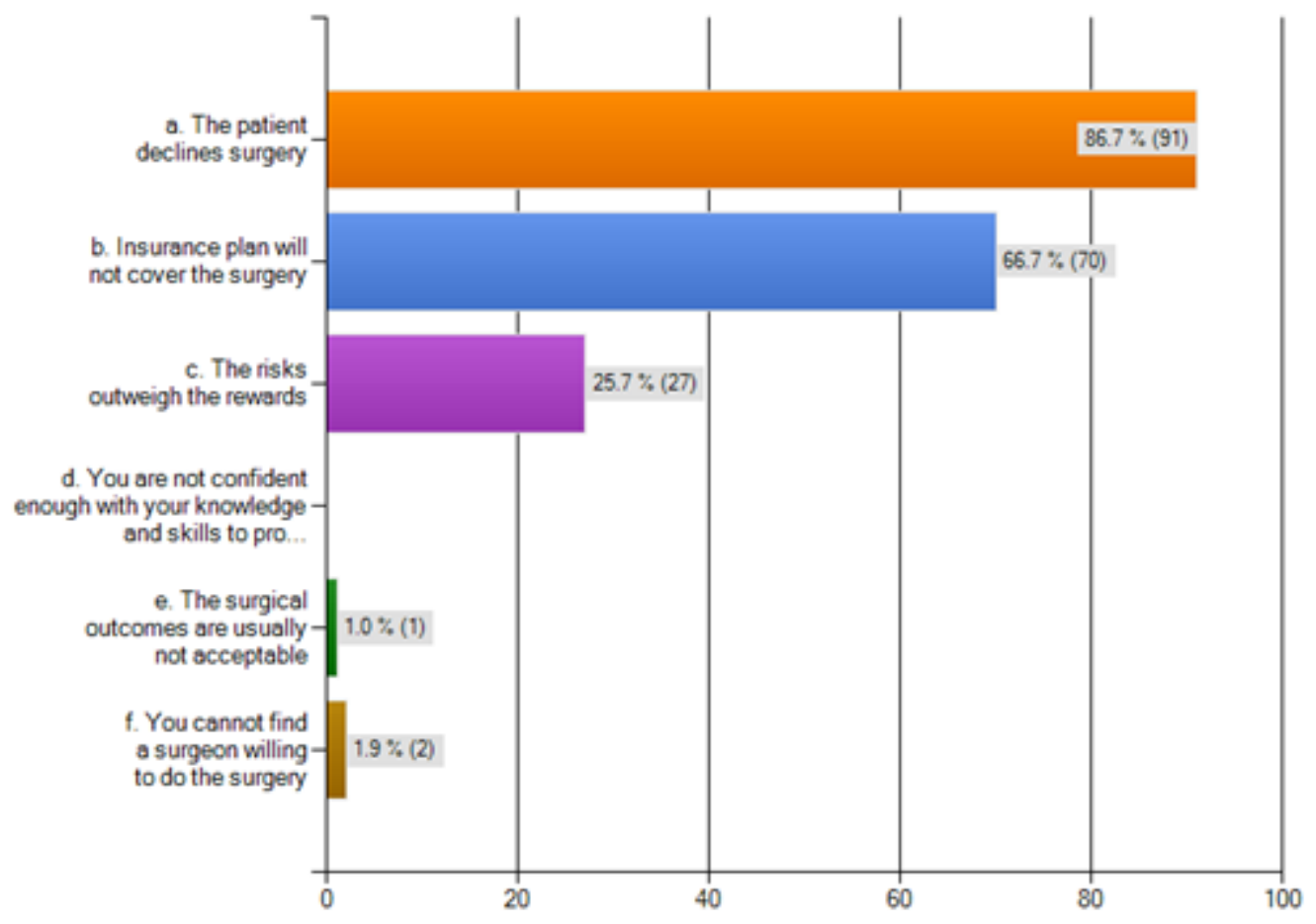

Figure 18 Survey Results: Reasons for declining surgery 


\section{Chapter VI: Discussion}

The purpose of this retrospective study was to evaluate the Four Faces of Orthognathic Surgery ${ }^{\circledR}$ in regards to surgical accuracy and the ability to transfer this method in an academic setting. An electronically submitted survey was also used to gain insight into issues pertaining to orthognathic surgery.

The private practice sample evaluated in this study shows that $100 \%$ of the patients were treated to within $1 \mathrm{~mm}$ of prediction. The mean for $\Delta \mathrm{X}$ was $0.50 \mathrm{~mm}$ and $\Delta \mathrm{Y}$ was $0.64 \mathrm{~mm}$ (Table 3 ). The university team sample had a greater variation in surgical accuracy than the private practice team but not a significant statistical significance in relation to the horizontal and vertical position of incision ( $\Delta \mathrm{X} P=0.18, \Delta \mathrm{Y} P=0.14)$ (Table 4). The mean of $\Delta \mathrm{X}$ for the university team was $0.76 \mathrm{~mm}$ and $\Delta \mathrm{Y}$ was $1 \mathrm{~mm}$ with $87 \%$ of the patients treated to within $2 \mathrm{~mm}$ of prediction and $53 \%$ treated within $1 \mathrm{~mm}$ of prediction (Table 3). Collectively, the data in this study indicated that approximately $94 \%$ of the patients had their maxilla placed within two $\mathrm{mm}$ of the prediction, and $75 \%$ were within one $\mathrm{mm}$ of the prediction. This is greater accuracy in comparison to similar studies that compared multiple teams' accuracy of a Le Fort I osteotomy. Semaan ${ }^{4}$ reported an accuracy rate of $66 \%$ within $2 \mathrm{~mm}$ and $25 \%$ within $1 \mathrm{~mm}$ of their sample of patients. Jacobson and Sarver ${ }^{2}$ reported from a private practice sample that $80 \%$ of the patients were within $2 \mathrm{~mm}$ of prediction and $43 \%$ were within $1 \mathrm{~mm}$. 
The question remains of the treated patients that were not in the $1-2 \mathrm{~mm}$ range of error just how far they were from the prediction. The data of this study showed the error in $\Delta \mathrm{X}$ and $\Delta \mathrm{Y}$ for the private practice team ranged from $-1 \mathrm{~mm}$ to $+1 \mathrm{~mm}$. (Table 3). The error in $\Delta \mathrm{X}$ for the university team ranged from $-1.5 \mathrm{~mm}$ to $+2.5 \mathrm{~mm}$, and the $\Delta \mathrm{Y}$ ranged from $-2 \mathrm{~mm}$ to $+3 \mathrm{~mm}$. This is a great improvement in comparison with similar studies that compared multiple teams' accuracy of a Le Fort I osteotomy. Semaan ${ }^{4}$ reported a range of incision in the horizontal direction $(-3.9 \mathrm{~mm}, 2.7 \mathrm{~mm})$ and $(-3.8 \mathrm{~mm}, 4.5 \mathrm{~mm})$ for the vertical direction for the private practice team. The teaching hospital team had a range of $(-6.8 \mathrm{~mm}, 5.5 \mathrm{~mm})$ for the horizontal direction and $(-2.8 \mathrm{~mm}, 4.2 \mathrm{~mm})$ for the vertical direction. Even Jacobson and Sarver ${ }^{2}$, had greater variation in their sample and both surgeons were established in a private practice setting. Surgeon 1 had a range of $(-3 \mathrm{~mm}, 4.7 \mathrm{~mm})$ for the horizontal direction and ($4.2 \mathrm{~mm}, 2.5 \mathrm{~mm})$ for the vertical direction. Surgeon 2 had a range of $(-4 \mathrm{~mm}$, $1.4 \mathrm{~mm})$ for the horizontal direction and $(-2.6 \mathrm{~mm}, 3.2 \mathrm{~mm})$ for the vertical direction.

The stability and predictability of orthognathic surgical procedures is reported to vary by the direction of the surgical movement, the type of fixation, and the surgical technique employed, largely in that order of importance. According to $\mathrm{Choi}^{35}$, the surgical complexity rate seems to be related with the result of the accuracy rate. In this sample of patients, refer to tables 9 and 10 , the direction that the maxilla was directed or the complexity of the procedure did 
not yield a statistical significant difference with surgical accuracy. These findings indicate the Four Faces of Orthognathic Surgery ${ }^{\circledR}$ is an accurate method regardless the surgical complexity or the primary direction of movement of the maxilla.

Why should accuracy be of concern to the orthodontist and surgeon? One $\mathrm{mm}$ of variance in the final position of the teeth can make a difference, especially in the smiling profile ${ }^{6}$. This places a great deal of responsibility on the oral surgeon and orthodontist to consistently achieve predictable and accurate results. Jacobson and Sarver ${ }^{2}$ have commented that an inaccurate surgery does not necessarily suggest that the surgical procedure was poor but only that is was different from the surgical plan. However, the argument could be made that if the treatment goals are not accurately attained routinely, the diagnostic and treatment planning protocol is undermined ${ }^{6}$.

In this study, regardless of who saw the patient first, there was good communication and agreement between the clinicians regarding the surgical goals. This may not be the trend in the normal private practice setting for orthodontists according to the survey. Among the orthodontists who responded the majority take a secondary role to the treatment planning and involvement with orthognathic surgery. Of the respondents to the survey, only $28 \%$ treatment plan the surgical movements, $41 \%$ participate in the model surgery, and $64 \%$ utilize a prediction tracing for a visual aid to demonstrate treatment. 
In order to assess accuracy, you must superimpose the prediction tracing on the post-surgical cephalograph or you cannot discern the accuracy of the surgery ${ }^{6}$. With only $14 \%$ of orthodontists doing a post-op superimposition on the prediction tracing, how would an orthodontist know if the result was different than the surgical plan or assess the accuracy? Yet the majority, $81 \%$ of the orthodontists, is pleased with the surgical result. $91 \%$ also reported that patients were satisfied. It is interesting to consider whether patients would prefer a planned outcome as opposed to the actual outcome.

Defining a successful surgery can be a subject of debate and a matter of opinion, and is outside the objectives of this study. However, since orthognathic surgery is elective and $1 \mathrm{~mm}$ of incision variance can make a difference $^{6}$, it is imperative that the surgeon/orthodontist strive to provide the patient with the most accurate surgical repositioning possible. ${ }^{24}$ This study shows the use of a surgical prediction tracing and demonstrates the need for communication between the involved clinicians to assure that they agree on a plan. It also shows the importance of superimposing the prediction tracing on the post-surgical cephalograph for a self-evalution on the accuracy. 


\section{Chapter VII: Summary and Conclusions}

The purpose of this study was to test the method of the Four Faces of Orthognathic Surgery $\AA$ in regards to surgical accuracy and the ability to transfer this method to an academic setting. An experimental group consisted of 15 patients from a university setting and 17 patients from a private practice setting. Radiographs were taken immediately prior to the orthognathic procedure and post-operatively within six weeks. Pre-surgical, post-surgical cephalometric radiographs, and the hand generated surgical predictions were collected from the sample. The prediction tracing was superimposed on the post-surgical cephalogram by cranial -base best fit. An XY coordinate system established by the transverse plane on the pre-surgical prediction tracing and transferred to the post-surgical cephalogram enabled measurements with a caliper of planned and actual linear changes to the maxillary incision. The differences of planned and actual changes to incision were then analyzed to determine whether or not a statistical significance existed regarding the following variables: surgical team, surgical complexity, and direction of maxillary movement. In addition, a survey was distributed to active members listed in the 2012-2013 American Association of Orthodontics to gain insight into issues regarding orthognathic surgery. 
The hypothesis was rejected as the following statistically significant changes were observed:

1. The Four Faces of Orthognathic Surgery ${ }^{\circledR}$ is a significantly accurate method of surgically repositioning the maxilla to a planned treatment goal.

2. The method of the Four Faces of Orthognathic Surgery ${ }^{\circledR}$ is a very transferable method to assure accurate repositioning of a maxilla in an academic setting. 


\section{Chapter VIII: Recommendations for Future Research}

Upon completion of this study, the following were recommended:

1. Repeat the study by increasing the sample size and evaluate the effect of statistical significance

2. Repeat the study employing the use of CBCT to evaluate actual changes of incision in 3-D rather than 2-D

3. Repeat the study with a sample size that is randomly selected throughout the United States at various surgical centers and assess the surgical accuracy.

4. A prospective study involving consecutive cases and confirmed agreement between the oral surgeon and orthodontist 


\section{References}

1. Miloro M, editor. Peterson's principles of oral and maxillofacial surgery. 2nd ed. BC Decker Inc.; 2004. .

2. Jacobson R, Sarver DM. The predictability of maxillary repositioning in LeFort I orthognathic surgery. Am J Orthod Dentofacial Orthop 2002 Aug;122(2):142-54.

3. William R. Proffit with Henry W. Fields, Jr. 2000(3rd Edition):1-742.

4. Semaan S, Goonewardene MS. Accuracy of a LeFort I maxillary osteotomy. Angle Orthod 2005 Nov;75(6):964-73.

5. Proffit WR, Turvey TA, Phillips C. The hierarchy of stability and predictability in orthognathic surgery with rigid fixation: An update and extension. Head Face Med 2007 Apr 30;3:21.

6. Timothy J. Tremont. The four faces of orthognathic surgery. 2010.

7. Van Sickels JE, Larsen AJ, Triplett RG. Predictability of maxillary surgery: A comparison of internal and external reference marks. Oral Surg Oral Med Oral Pathol 1986 Jun;61(6):542-5.

8. Mankad B, Cisneros GJ, Freeman K, Eisig SB. Prediction accuracy of soft tissue profile in orthognathic surgery. Int J Adult Orthodon Orthognath Surg 1999;14(1):19-26.

9. Reyneke JP. Essential of orthognathic surgery. 2nd Edition ed. ; 2010. .

10. Gil JN, Claus JD, Manfro R, Lima SM,Jr. Predictability of maxillary repositioning during bimaxillary surgery: Accuracy of a new technique. Int $\mathrm{J}$ Oral Maxillofac Surg 2007 Apr;36(4):296-300.

11. Fonseca R, J. Oral and maxillofacial surgery volume 2-orthognathic surgery. 2000; Volume 2.

12. Kahnberg KE, Sunzel B, Astrand P. Planning and control of vertical dimension in le fort I osteotomies. J Craniomaxillofac Surg 1990 Aug;18(6):267-70.

13. Rau BM. The editors of langenbeck's since 1860. Langenbecks Arch Surg 2010 Apr;395 Suppl 1:13-6. 
14. Cheever D. B.J.Oral Maxillofac.Surg. 1867:162.

15. Le Fort R.

Fractures de la machoire superieure. Rev Chir 1901:4:360.

16. Gross BD, James RB. The surgical sequence of combined total maxillary and mandibular osteotomies. J Oral Surg 1978 Jul;36(7):513-22.

17. Bell WH, Condit CL. Surgical-orthodontic correction of adult bimaxillary protrusion. J Oral Surg 1970 Aug;28(8):578-90.

18. Kent JN, Hinds E. Management of dental facial deformities by anterior alveolar surgery. J Oral Surg 1971 Jan;29(1):13-26.

19. Connole PW, Small EW. Combined maxillary and mandibular osteotomies: Discussion of three cases. J Oral Surg 1971 Aug;29(8):572-8.

20. Epker BN, Wolford LM. Middle-third facial osteotomies: Their use in the correction of congenital dentofacial and craniofacial deformities. J Oral Surg 1976 Apr;34(4):324-42.

21. Oatis GW,Jr, Van Belois HJ, Sugg WE,Jr. Combined surgical procedures to correct facial deformities. J Am Dent Assoc 1978 Jul;97(1):58-65.

22. Oatis GW,Jr, Grisius RJ, Sugg WE,Jr. Combined surgical procedures to correct facial deformities: An update. Oral Health 1981 Oct;71(10):37-41.

23. Obwegeser $\mathrm{H}$.

Eingriffe an oberkiefer zur korrektur des progenen. 1965; Vol 75.:p. 356.

24. Polido WD, Ellis E,3rd, Sinn DP. An assessment of the predictability of maxillary surgery. J Oral Maxillofac Surg $1990 \mathrm{Jul} ; 48(7): 697-701$.

25. Krekmanov L, Lilja J, Ringqvist M. Simultaneous correction of maxillary and mandibular dentofacial deformities without the use of postoperative intermaxillary fixation. A clinical and cephalometric study. Int J Oral Maxillofac Surg 1988 Dec;17(6):363-70.

26. Stanchina R, Ellis E,3rd, Gallo WJ, Fonseca RJ. A comparison of two measures for repositioning the maxilla during orthognathic surgery. Int $\mathrm{J}$ Adult Orthodon Orthognath Surg 1988;3(3):149-54. 
27. Polido WD, Ellis E,3rd, Sinn DP. An assessment of the predictability of maxillary repositioning. Int J Oral Maxillofac Surg 1991 Dec;20(6):349-52.

28. Aharon PA, Eisig S, Cisneros GJ. Surgical prediction reliability: A comparison of two computer software systems. Int J Adult Orthodon Orthognath Surg 1997;12(1):65-78.

29. Bryan DC, Hunt NP. Surgical accuracy in orthognathic surgery. $\mathrm{Br} \mathrm{J}$ Oral Maxillofac Surg 1993 Dec;31(6):343,9; discussion 349-50.

30. Cangialosi TJ, Chung JM, Elliott DF, Meistrell ME,Jr. Reliability of computergenerated prediction tracing. Angle Orthod 1995;65(4):277-84.

31. Eckhardt CE, Cunningham SJ. How predictable is orthognathic surgery? Eur J Orthod 2004 Jun;26(3):303-9.

32. Upton PM, Sadowsky PL, Sarver DM, Heaven TJ. Evaluation of video imaging prediction in combined maxillary and mandibular orthognathic surgery. Am J Orthod Dentofacial Orthop 1997 Dec;112(6):656-65.

33. Zhang X, Wang X, Zhang Z. Accuracy of computerized aid diagnosis, surgical simulation and facial appearance prediction in orthognathic surgery. Zhonghua Kou Qiang Yi Xue Za Zhi 1998 Jan;33(1):6-9.

34. Gerbo LR, Poulton DR, Covell DA, Russell CA. A comparison of a computer-based orthognathic surgery prediction system to postsurgical results. Int J Adult Orthodon Orthognath Surg 1997;12(1):55-63.

35. Choi JY, Choi JP, Baek SH. Surgical accuracy of maxillary repositioning according to type of surgical movement in two-jaw surgery. Angle Orthod 2009 Mar;79(2):306-11.

36. Sharifi A, Jones R, Ayoub A, Moos K, Walker F, Khambay B, McHugh S. How accurate is model planning for orthognathic surgery? Int $\mathrm{J}$ Oral Maxillofac Surg 2008 Dec;37(12):1089-93.

37. Bailey JO,Jr, Nowlin TP. Evaluation of the third point of reference for mounting maxillary casts on the hanau articulator. J Prosthet Dent 1984 Feb;51(2):199-201.

38. Kwon TG, Mori Y, Minami K, Lee SH. Reproducibility of maxillary positioning in le fort I osteotomy: A 3-dimensional evaluation. J Oral Maxillofac Surg 2002 Mar;60(3):287-93. 
39. Ellis E,3rd. Bimaxillary surgery using an intermediate splint to position the maxilla. J Oral Maxillofac Surg 1999 Jan;57(1):53-6. 